\title{
Commonplace:
}

Towards a post-ethnic understanding of identity and representation of Asian New Zealanders for museum practice

A dissertation submitted to the Victoria University of Wellington in partial fulfillment of the requirements for the degree of Master of Museum \& Heritage Studies

\section{Vera Mey}

2010 


\section{Abstract}

Displays of national identity in the context of the social history exhibition focus on the universal as a method of connecting a diverse group of people. The issue with this approach for Asian New Zealanders is the vexed and complex process of identity making and their contested representational history. Being Asian in New Zealand is inevitably tied to an offshore repository of signs and signifiers whilst a local presence alludes to a peripheral experience. This dissertation considers the museum not as a mirror but as a manifesto and privileges the encounter between the exhibition and the exhibited subject.

Considering recent identity theories such as hybridity and cosmopolitanism, this dissertation provides fresh perspectives to explore processes of representation within the museum. The two perspectives examined are representation within the museum exhibition Passports at Te Papa Tongarewa and processes of identity making through narrative biographies of 'later' generations of Asian New Zealanders. Examining these two sides of representation is a means to evaluate the efficacy of representation within the civic space of the museum. Narrative interviews were conducted using a longitudinal approach. Two separate interviews, with the first in the museum setting, allowed for an exploration of how representation and meaning precedes and succeeds the confrontation with an exhibition.

The empirical material reveals that for the participants in this study the focus is no longer on migration and being from 'somewhere else' but rather navigating and negotiating multiple identities as a result of circumstances located in this time and place. The term 'Asian' in New Zealand holds its own meaning beyond geographic markers and in this research accounts more for the idea of a type of communal experience as opposed to traditions bound by ethnic specificity. This research aims to fill a dearth in empirical testing of identity theory as well as reveal an understanding of the potential of the person as a signifier. Viewing the exhibition as an influence on identity making allows for a realisation of how feelings of belonging are shaped within the museum's walls, and how the exhibition holds influence going beyond this site of encounter. 


\section{Acknowledgements}

Firstly, this dissertation would not have been possible without the support and guidance of my supervisors Dr. Lee Davidson from the Museum \& Heritage Studies department at Victoria University of Wellington and Sean Mallon, Senior Curator- Pacific, Te Papa Tongarewa. I have learnt that these conversations 'in the field' are an invaluable part of the research process. For your patience, knowledge and editing guidance, I am grateful. Dr. Conal McCarthy, Director of the Museum \& Heritage Studies programme, has been influential in my articulation of Museum \& Heritage Studies and its wider relationship to other disciplines. Thank you for being an incredible and encouraging educator.

Meetings with Hannah Ho, Kirsten Wong, Stephanie Gibson and Dr. Christopher Fung have also been formative in terms of ideas and thoughts surrounding this dissertation. Hyekung Chung from the university library was wonderful helping with resources. Jackson James Wood was generous with his editing skills, thank you. My fellow Masters' classmate Chloe Searle was a shoulder of support. Thank you for enduring all my bouts of academic self-doubt, philosophical tirades and encouraging me to keep going when I was considering throwing my toys in. Also thank you to Benjamin John Fraser, Miranda Tindill and Linley Bruce for providing domestic support.

Thank you to the participants. Your honesty and intelligence has enriched this research. Without your stories this dissertation would be hollow.

Finally, my love, respect and thanks to my parents Chhoeung Mey and Siti Sulastri. I am grateful for your persistence in the belief that it is important to know and appreciate who you are, where you come from, and the myriad of human relationships that shape our feelings of belonging in relation to each other and to the world. I hope this sense of enquiry resonates within the following pages. 


\section{Table of contents}

$\begin{array}{ll}\text { Abstract } & \text { ii }\end{array}$

Acknowledgements

Chapter 1: Introduction $\quad 1$

A brief history of Asian New Zealanders and their representation 5

Te Papa's role in making and reflecting public history 9

Museums and social inclusion $\quad 11$

Identity theory 14

Representation as both a tool and process for response 19

Summary 22

Chapter 2: Methodology

Introduction $\quad 24$

Rationale $\quad 25$

The interviews $\quad 27$

The participants $\quad 29$

$\begin{array}{ll}\text { Analysis } & 30\end{array}$

Chapter 3: Reacting

Introduction $\quad 34$

Reacting to representation $\quad 35$

Passports 36

Responses to Passports 38

Summary $\quad 42$

Chapter 4: Constructing

Introduction 44

Being the same but different $\quad 47$

Public versus private identities $\quad 54$

The difference between being and seeing Asian 57

Summary: perspective $\quad 64$

Chapter 5: Navigating

Introduction 66

From ethnic to cultural category: affinity as the unifier 68

$\begin{array}{ll}\text { Choice } & 71\end{array}$

Beyond ethnicity $\quad 74$

$\begin{array}{ll}\text { Towards a commonplace } & 77\end{array}$

Summary $\quad 83$

$\begin{array}{ll}\text { Chapter 6: Conclusion } & 85\end{array}$

$\begin{array}{ll}\text { Bibliography } & 91\end{array}$

$\begin{array}{ll}\text { Appendix } 1 & 98\end{array}$

$\begin{array}{lr}\text { Appendix } 2 & 99\end{array}$

$\begin{array}{ll}\text { Appendix } 3 & 100\end{array}$ 


\section{Chapter 1: Introduction}

While not so many have been murdered for explicitly aesthetic reasons, nonetheless, art is as fundamentally dangerous and life-threatening as religion continues to be, even if both art and religion may also at times have had some well-documented redeeming qualities (Preziosi, 2009: 2).

In the above excerpt Preziosi talks about the commonalities between art and religion. His central idea that "art is dangerous" has lingered in my mind since I heard these words spoken at a seminar some years ago and remains paramount to this dissertation. If we abstract this idea but retain the approach we can see a link between art and representation. Art is dangerous; art is representation, therefore representation is dangerous. It shows how art/representation reveals a process for thinking about and understanding the world. In the context I first heard Preziosi use this idea he cited the example of the cartoons of Mohammad that were published in Denmark inciting a violent response from offended Muslim extremists. This is a direct cause and effect example of how representation has the potential to evoke danger.

The representation this dissertation will focus on is, thankfully, not as volatile but still retains a socio-political element. This dissertation explores the processes of representation using Asian New Zealanders as the central case study. I examine their responses to being represented by a museum and look at how they create their own representation through narrative biographies. Through this research the museum is considered not as a mirror but a manifesto exposing the relationship between the represented person and their own conceptions of ethnic identity and how they consider their histories. This is done in order to better understand the processes of identity construction for migrants and to consider the implications of this for museum exhibitions that represent them. This is framed within the context of recent identity theories including hybridity and cosmopolitanism. 
I am using Asian New Zealanders as a starting point for ways to think about and understand processes of representation. This study focuses on the metaphor of the exhibition as fertile ground for the encounter between representation and the represented person themselves. The social history exhibition Passports has been used as a catalyst to think about national representation at the Museum of New Zealand Te Papa Tongarewa, the site where the narrative interviews with Asian New Zealanders took place. Museums are spaces where representation is created and negotiated (Mason, 2005). This dissertation considers the museum as a metaphor for national understanding of the situation of non-Māori migration, and as a site which has potential to alter public thought and impact on feelings of belonging in a social group. This research is undertaken to expose the potency of representation and its implicit connection and effect on real people.

Contemporary identity theory suggests we have moved beyond essentialist ideas about ethnicity and nationality (Araeen, 2008). This dissertation is an enquiry into the situation we are now in. Public museums are inherently political spaces and act as not only arbiters of taste but also of how to think about and understand the world (Lidchi, 1997), they are "safe places for unsafe ideas" (Gurian, 2010). ${ }^{1}$ Their task is inevitably dangerous.

Following the principles of Kaupapa Māori research towards a more socially responsible and ethical study of culture (Walker, Eketone \& Gibbs, 2006), I have placed this dissertation within an auto-ethnographic context by studying a community group I personally affiliate with (Denzin 1989: 34). This group is what I consider the 'later' generations of Asian New Zealanders, that is, $1.5,2^{\text {nd }}$ and $3^{\text {rd }}$ generations or of mixed ethnicity. Because of my own positioning, I align myself as one of the participants of this research, and as an Asian New Zealander. I mark this position through the use of 'we' when referring to Asian New Zealanders.

${ }^{1}$ I heard Elaine Heumann Gurian say this at a seminar on 19 April 2010. 
This dissertation is a response to the proliferation of identity theory buzzwords produced by social theorists, ideas which have been understudied empirically. Do concepts like hybridity (Araeen, 2002) or cosmopolitanism (Kendall, Woodward \& Skirbis, 2009) correspond to the way people actually understand and relate to each other? To complement the inquiry into processes of identity making, representational processes are also interrogated to ascertain whether or not there is a correlation between representing yourself, through narrative biography, and being represented, through the public museum.

To illustrate the spectrum of representation from initial biography to final realisation of a representational 'product' of the exhibition, I examined the idea of social history in a civic space in comparison to narrative interviewing of the 'later' generations of Asian New Zealanders. Hall's circuit of culture model has been appropriated to show the tension between representation as reactive and reflective and representation as autonomous and self-determining (1997: 1), (appendix 1). ${ }^{2}$ This research reveals what emerges in the encounter between a person and their representation.

The decision to examine narrative interviews of Asian New Zealanders does not merely serve auto-ethnographic purposes but is also an attempt to contribute to New Zealand studies on an ethnic group with a fast growing population but contentious history of representation in this country. The studies of Asian New Zealanders have so far been ethnically specific, such as mapping a history of Chinese New Zealanders since initial settlement in 1842 , and this collective social group and the ambiguity of the 'Asian' experience in New Zealand is yet to be properly examined (Te Ara Encyclopedia of New Zealand). ${ }^{3}$ This dissertation takes a cue from the Asia:

\footnotetext{
2 Please see Appendix 1 for an image of this diagram.

${ }^{3}$ http://www.teara.govt.nz/en/chinese.
} 
New Zealand Foundation in using the term Asian to understand what this means within the context of New Zealand. ${ }^{4}$

Museums are spaces where categorisation and classification are imposed; where representation is the means for communication and interpretation (Mason, 2005). Museological literature has focused on representation either being theoretically based from a curatorial level or from a quantitative perspective looking at visitor demographics or studies of responses to exhibitions at a reactionary level. This study is an attempt to examine on a broad, conceptual level how representation in the civic space of the national museum which is tasked with standing for and of the nation (Mason in Waite, 2009) impacts on feelings of acceptance and belonging within a social group. The exhibition Passports at Te Papa Tongarewa will be examined as an example of national understanding of Asian New Zealanders in the forum of public history.

This chapter introduces some of the main theories that have influenced my research as well as providing assistance to understanding the central ideas of this dissertation. This dissertation draws upon interdisciplinary ideas and theories. From art theory, cultural studies and museum and heritage studies I used theories about interpretation and methods of understanding representation. Asian studies and post-colonial studies have been used to situate the case study and the political situation of Asian New Zealanders. Sociology has been inserted where appropriate to examine the way communities are made and understood. Methodological approaches were appropriated and adapted from the social sciences field. I provide an overview of the way Asians have been shaped in New Zealand's history and discuss theory which questions how these epistemologies are upheld. I then talk about contemporary identity theory and new ways that are being explored to fathom the situation of Asian New Zealanders and their

${ }^{4}$ Countries of Asia as classified by the Asia New Zealand Foundation are: Bangladesh, Bhutan, Brunei Darussalam, Burma (Myanmar), Cambodia, China, Chinese Taipei, Hong Kong SAR, India, Indonesia, Japan, Laos, Malaysia, Mongolia, Nepal, Pakistan, Philippines, Singapore, South Korea, Sri Lanka, Thailand, Timor-Leste and Vietnam (Asia: New Zealand Foundation). http://www.asianz.org.nz/countries-asia. 
representation. This process has strong ties with representation theory which I discuss to look at the way people construct themselves and how they are being constructed through material and visual culture, and sites that accommodate this such as the museum. I then look at museological theory and the role of the museum in terms of social responsibility and the importance of cultural safety within representation. This leads me on to Te Papa and their permanent exhibition Passports.

This dissertation is not fixed to a singular disciplinary framework. Instead it is informed by fields which overall connect to the interdisciplinary framework of museum \& heritage studies. A limitation is that the size of this dissertation means I am only able to scratch the surface of these issues, however it is intended that this research can contribute to other work on national and ethnic identity within museums as well as other literature within Asian studies on identity politics.

This research attempts to fill a gap in the literature for museum \& heritage studies by showing a broader approach to the field through investigating the nature of representation and its ramifications beyond the museum walls. Representation may have its locus in the public exhibition but its causes and effects precede and succeed the encounter of the museum.

\section{A brief history of Asian New Zealanders and their representation}

Because this is a study of the process and effects of representation, perhaps the best examples to show the state of representing Asian New Zealanders is exemplified by two images (Appendix 2). Both are derived from publically available media sources. They are a hundred years apart but depict an uncomfortable similarity.

Deborah Coddington's article subtitled with the phrase "is it time to send some back?" confrontingly displays the way that Asia and Asians have become New Zealand's "other." Said's theory that "orientalism is a style of thought based upon an ontological and epistemological distinction made between 'the Orient' and (most of the time) 'the Occident' " (2003:2) can be 
applied to New Zealand's interaction and representation of Asia since the initial arrival of Asians in New Zealand in 1842 (Te Ara). ${ }^{5}$

To reconfigure New Zealand as a multicultural and cosmopolitan nation Phillips has described New Zealand as a "nation of immigrants" (Phillips, 2001: 148). This idea was adopted when developing the exhibition Passports at Te Papa: an exhibition which looks at the peopling of New Zealand and takes a celebratory approach to Tangata Tiriti (Te Papa Concept Plans, 1996), a collective group of different ethnicities who represent biculturalism's non-Māori other half and who came here by rights established by the Treaty of Waitangi (Te Ara). ${ }^{6}$ The "nation of immigrants" idea does not account for those who exist in a liminal state as neither Tangata Whenua nor Pākehā Tangata Tiriti. ${ }^{7}$ It also does not acknowledge that within the representation of New Zealand history there has been a conscious construction of exclusions within the Tangata Tiriti category, revealing how it is not a cohesive collective but rather one of disparate ethnic groups. The term Pākehā is generally associated with people of European heritage (ibid).

The first Asian presence within New Zealand were the Chinese gold miners of the 19th Century (McKinnon, 1996; Phillips, 2006; Te Ara). This group faced overt discrimination by Government disincentives such as specifically taxing Chinese migrants to New Zealand on arrival (Te Ara). ${ }^{8}$ McKinnon argues that New Zealand has always been a nation of immigrants with the earliest settlers arriving in 1840 but that these migrants were more of the kin-migration category (Mckinnon, 1996). He argues that the influx of migrants from Britain perpetuated a New Zealand identity built on British values and a white population. McKinnon further reveals that "(British)

\footnotetext{
5 http://www.teara.govt.nz/en/chinese/2.

6 http://www.teara.govt.nz/en/the-new-zealanders/12

7 Tangata Tiriti has been conventionally understood as Pākehā, which in turn has also been understood to be someone white and of European heritage. (Te Ara) http://www.teara.govt.nz/en/the-new-zealanders/12

8 Known as the Chinese poll tax. In 2002 Prime Minister Helen Clark formally apologized for this (Te ara). http://www.teara.govt.nz/en/chinese/3.
} 
immigrants and the New Zealand born, while different, were not as foreigners to each other" (ibid). This is significant in the modern formation of the potential of what a New Zealander can be. It explains why $1^{\text {st }}$ generation British or South African people fit more easily within this term than a $2^{\text {nd }}$ or $3^{\text {rd }}$ generation person of Chinese heritage.

McKinnon goes on to argue that Pacific Islanders were spared from being considered alien because they were seen as a "different kind of Māori" (McKinnon, 1996: 40). His historical account of Asian presence in Aotearoa shows how Asian people were excluded from the term New Zealander:

This act, by defining no other categories than those of New Zealand citizens and of others, abolished the distinction between 'commonwealth' and 'foreign', effectively substituting for it the distinction between 'New Zealand' and 'foreign'... while the boundary between 'British' and 'foreign' was blurred, that between 'European' and 'non-European' remained (1996: 43).

McKinnon's argument provides insight into the way Asian people were separated from being assimilated into the New Zealand mainstream because of ideas about race and difference. The term Asian itself was highly contested because "by imposing a collective label; it fosters a belief in an illusory homogeneity and separateness" (McKinnon, 1996: 56). The weight of this history of being "non European" in an increasingly bicultural Aotearoa still resonates today.

Fong outlines the three main factors contributing to construction of the Chinese as to be feared and thus outside of being New Zealanders: "these factors are economic competition, suspected immorality, and the idea that colour races were inferior to white people" (1959: 9). She presents an argument that suggests the power dynamic in New Zealand ensured the marginality of Chinese people in New Zealand not only because of racial characteristics but also because in the global political arena the dominant culture was European (Fong, 1959: 11).

Fong further discusses the issues with assimilation and acculturation and describes how despite a Chinese person diluting their Chineseness, there 
was "no guarantee of being accepted by the dominant society" (Fong, 1959: 45). She also highlights the desire to be accepted under the New Zealander umbrella and that "the Chinese have not a single institution that would encourage them to resist assimilation. They have no desire to be exclusive" (Fong, 1959: 131).

The idea of Asian as sojourner shifted to the idea of Asian as model minority where Chinese groups were expected to keep a low profile and assimilate quietly into the status quo (Ip \& Pang, 2005). There later existed a new disparity between older Chinese migrants, new migrants and other Asian people who were enveloped into this Asian category further confusing categorisation of what the term 'New Zealander' and 'Asian' could encompass (Ip \& Pang, 2005).

Fong (1959), Ip \& Pang (2005), and McKinnon (1996) have argued that the Asian group category exists as outside of the mainstream and something that was constructed as incompatible with the term New Zealander which contradicts Phillip's harmonious version of New Zealand and his inclusive approach. For Ward \& Lin, non-Europeans are deemed ethnic groups which exist outside the status quo and treated as periphery, "perceived and labeled as 'ethnic groups' "(2005: 162).

Cormack's thesis on Asian representation through media determines the way Asians have been perceived as threat, impermanent, commodity, and as victim (Cormack, 2007). Her thesis provides a comprehensive study of the construction of the Asian "Other." Her focus on the two dimensional realm of mass media and parliamentary texts revealed how the idea of being 'Asian' implied an offshore identity or reference point constructed as incompatible and different to New Zealand (Cormack, 2007).

The way identity has been looked at by the above studies is as something static and created outside of the person. My study is more focused on the ambiguity of both that term 'Asian' and its offshore allusion. I will explore the manifestation of "hybrid" which I will later discuss in this chapter. I am influenced by Mok's sentiments towards the ambiguity of Asian ethnic 
identity and use the term 'Asian' in a relatively broad and inclusive manner. Perhaps the best way to describe this feeling of relating to being Asian is exemplified by her anecdote:

When the anonymous skinhead punched Chi Phung in the chest and ran, Phung, a tiny, pigtailed Vietnamese student of sociology, lay crumpled and crying on a Christchurch sidewalk for twenty minutes... I've slipped unnoticed through near-rioting South-east Asian streets, and passed unscathed through China, Central Asia and the Middle East, there are parts of this country where the promise of my passport's protection isn't enough to put me at ease. Is it the same for you? If so, then for the next few pages, you are my people (Mok, 2004: 19).

So far the arguments I have focused on concentrate on the idea of assimilation or acceptance into the idea of being a New Zealander. I have also tried to show that being an Asian New Zealander is a unique experience because of a specific representation through history and the ambiguity of what the term 'Asian' refers to. It is a different experience to other migrant groups in New Zealand, it is not equal as being another immigrant within "a nation of immigrants." The next section looks at Te Papa's role in representing the cultures of New Zealand and the approach they have taken to achieve this.

\section{Te Papa's role in making and reflecting public history}

The Museum of New Zealand Te Papa Tongarewa aspires to represent the peoples of New Zealand in an inclusive and accessible manner (Te Papa, 2009-2012: 4). Te Papa presents itself as a forum for the nation (ibid). This is done through collections, education, national outreach support to other New Zealand museums and scholarship (ibid). The museum has a premise of biculturalism and considers this fundamental to its operational structure (ibid).

Te Papa opened in 1998, having evolved from the Dominion Museum and National Art Gallery (Te Papa). ${ }^{9}$ When Te Papa opened, Passports was part

${ }^{9}$ http://www.tepapa.govt.nz/AboutUs/history/Pages/default.aspx\#1998 
of the Day 1 exhibitions (Te Papa Concept Plans 1996 in Waite, 2009) and is part of the museum's direction to present ideas in an interdisciplinary, narrative based and interactive way (Te Papa, 2009-2012). ${ }^{10}$

In Te Papa's Statement of Intent there are two parts which are directed towards an understanding and representation of the diverse demographic of New Zealand. ${ }^{11}$ In terms of Te Papa's functions a key mission is to "have regard to the ethnic and cultural diversity of the people of New Zealand, and the contributions they have made and continue to make to New Zealand's cultural life and the fabric of New Zealand society" (Te Papa 2009-2012: 4).

What is noticeable is Te Papa's focus on the future and the present. Something that will be further discussed and kept in mind throughout the analysis is whether or not the national museum should be reflective or aspirational.

In terms of fostering cultural diversity part of this is achieved through the Community Gallery, a section of Te Papa devoted to celebrating social groups in New Zealand by collaborating on exhibitions. ${ }^{12}$ This process faced difficulties in the past because of the ambiguity in terms of community contribution and conflicts between Te Papa listening to the needs and desires of the community and actual delivery on the exhibition floor (Ballard, 2005; Wood, 2007). However a lot of these problems have been resolved with the addition of a Community Relations Manager (Ballard, 2005).

Ballard (2005) and Waite (2009) have respectively looked at Te Papa's role in creating public history and the rigorous debate surrounding what eventuates on the exhibition floor on both a curatorial (Waite, 2009) and

\footnotetext{
10 http://www.tepapa.govt.nz/AboutUs/history/Pages/default.aspx\#1998 11 "Museum of New Zealand Te Papa Tongarewa (Te Papa) is a forum for the nation to present, explore, and preserve the heritage of its cultures and knowledge of the natural environment in order to better understand and treasure the past, enrich the present, and meet the challenges of the future" (Te Papa, 2009-2012: 4).

12 The focus of this gallery has been on a 'non-iwi community of shared heritage or interest' (Te Papa, 2009-12: 16).
} 
community level (Ballard, 2005). This study will expand on their groundwork and look at the relationship between the represented person and the exhibition in which they are represented and their own processes of interpreting their histories, to arrive at ideas for better representation for social inclusion.

\section{Museums and social inclusion}

Museums are theatres for identity making. Mason regards audiences as "consumers and producers of meaning" (2005: 208) where communities relate to interpretative material according to their affinity with the target community group or information on display. For example she cites Fish's idea of interpretative communities where groups are defined along "historical and cultural experiences," "specialist knowledge, demographic/socio-economic factors," "identities (nation, regional, local, or relating to sexuality, disability, age and gender)," "visiting practices" and "communities defined by their exclusion from other communities" (2005: 206-207). She believes that people are able to assume different community associations because of conceptual maps where people can simultaneously affiliate with differing community values and are not confined to one group (ibid).

Mitchell (1998) discusses how the exhibition is a microcosm that holds a particular view of certain cultures. Historically this view has been controlled by a singular culture because it shows a "single system of understanding which brings together the human diversities of the present and the past, and the natural world of the Other outside our own species, into a coherent pattern" (Pearce 1996: 16).

This strategy is still employed by museums like Te Papa where different ethnicities are grouped together in the same space. However, this is not necessarily done in order to manipulate control of the group represented but rather as a method for equalising difference. Phillip's idea of Passports as showing a "nation of immigrants" aimed to do that where all non Māori occupy the same exhibition space (1996). 
Hooper-Greenhill puts forth the idea that it would be culturally unsustainable to have "monolithic white histories" and that "museums that construct and continue to communicate an unmediated white culture" are at risk of becoming irrelevant and redundant (1997: 5). For museums to stay relevant as public institutions she argues that a restructuring of the narrative of museums is paramount because she believes "these histories and cultures construct exclusions" (ibid).

Te Papa is moving towards this by handing over some control of the exhibition process to community groups, and this aligns with HooperGreenhill's argument that "communities cannot be invented to suit museums" (1996: 6-7). Hooper-Greenhill criticises museum approaches that are neutrally passive or celebratory in the representation of ethnic minorities (1996: 9). Philips' "nation of immigrants" idea has had little effect on the way Asian New Zealand identity is understood as it focuses too superficially on the idea of celebrating difference despite the fact that it is this very construction of difference which is disparaging and detrimental to social inclusion. This approach ignores a history of discrimination and does not acknowledge the disparity between celebration and the fact that these cultures are still representationally marginalised.

Sandell's study of the act of tolerance and toleration within museums focuses on the process of meaning making through language used in response to exhibitions. Sandell argues that museums have the potential to reframe prejudice by allowing conversations about it as opposed to concealing its signifying practices (2007: 173). He views the forum of the museum "as a resource, amongst many, on which audiences might draw in shaping their individual and collective social understandings" (2007: 172).

Newman further emphasises the responsibility museums have in creating human, social, cultural and identity capital in affecting the lives of visitors (2005). This circuit of cultural capital involves the museum in the process of creating messages through encoding. Visitors must then interpret and decode these messages in relation to their own epistemologies. He argues 
that museums control this act of encoding and that they must create codes which ensure the inclusion of visitors.

Sandell's study of the manifestation of prejudice involved examining the language used in visitor comments' books and interviewing participants after an exhibition visit (2007). He looked at attempts to eradicate prejudice by museums and at the type of language used in exhibitions dealing with themes of tolerance to examine whether the mission of the museum was achieved after the visit. His results were qualitative and varied in response. A mix of people were changed and more tolerant and respectful after their visit but there were also some whose intolerant views were not altered and who shunned the sight of something that did not comply with their world view. He borrows from Hall whose "analysis of media communication, in which he blurs the distinctions between processes of production and consumption, has contributed to a radical reconceptualisation of media-audience relations" (2007: 76). Sandell's anaylsis of responses to representation reveal the importance of understanding how people used their own epistemology to understand museum messages.

Sandell uses a constructivist approach to his study where it is understood that "visitors should be enabled to bring their life experiences to bear in creating a meaningful encounter with the museum's displays" (2007: 78). Meaningful encounters are encouraged by being confronted with material that has connection to the life of the visitor or is open enough to allow access from a multitude of perspectives (2007). Sandell divided his responses into: confimatory, oppositional or negotiated responses to museum codes (2007: 80).

The theory that visitors draw on their pre-existing knowledge is endorsed by Mason, who discusses how "meaning is not fixed within objects...but is produced out of the combination of the object/the image/the site itself/the mode of presentation, what is known about its history and production, and visitor interaction" (2005: 203). 
The combination of the person's own epistemology coupled with the museum's shows how processes of representation precede and succeed exhibition encounters. Representation is always in flux even though objects are static. Museums are storehouses of preserved, categorised objects, however meaning and knowledge is never fixed and neither are identities or our relationships to both objects and our history. The next section deals with how meaning making changes through the perspective of identity making, with contemporary theory suggesting that these ideas of preservation and categorisation are incompatible with the way people think about their identities and relationships surrounding this. I aim to show that within these ideas are avenues for reading and understanding the position of Asian New Zealanders today.

\section{Identity theory}

The premise behind ethnicity is that it is located in geographic and cultural specificities (Pieterse, 2005: 172-173). Categorising people into identity categories through ethnicity is seen by Tate to "freeze identities." He instead suggests the idea of hybridity. For Tate hybridity is a cultural positioning where "analysis in the postcolonial and pre-imperial mode begins." This positioning allows people to remain unconfined to their offshore identities and the reference points that those identities entail (Tate in Pieterse, 2005: 173). With the acknowledgement that people are in hybrid positions comes the deconstruction of traditional museum discourse because of the redefinitions surrounding ethnic categories.

Araeen has a similar articulation of hybridity but locates it in a much more specific situation. His idea is more prescriptive in the sense that hybridity only emerges "when a non-western culture enters western culture" (Araeen, 2002: 338). He calls this space an "in-between space" where the non-western person has access to the dominant western culture but is still not subsumed into it (ibid). In order for the non-western person to approach western culture they use "cultural identity cards" which, for example, manifest themselves through hyphenating identities such as Asian 
New Zealander. In the 2006 New Zealand Census form only one ethnicity was connected to the term New Zealander which was "European New Zealander" (Statistics New Zealand, 2006).Other ethnicities were not able to disclose their prescribed identity along with the term New Zealander despite Statistics New Zealand determining that ethnicity is something "self-perceived" and that "ethnicity is not the same as birthplace" (Statistics New Zealand). ${ }^{13}$

Rouse also comments on this incessant need to hyphenate or affiliate artists within a particular paradigm and how this can place "conceptual constraints on the potential of what people can be defined as" (Rouse, 2007: ii). She questions if there is possibility for definition "beyond [the] culturalist paradigm" (ibid).

Identifying as or being hybrid places the person within a strategic political positioning that has access to both ethnicities. By identifying as hybrid a person has access but also is excluded from being completely assimilated through being unlocated as neither dominant nor peripheral. Araeen's theory easily applies to the situation of Asians in New Zealand where they have been constructed as not only Asian but also non-European and do not as readily have access to the term Pākehā. The benefit of hybridity is that it is not about identifying with one or the other or even both identities, there is a sense of positioning that does not relinquish to either prescriptions.

The focus on hybridity is less to do with ethnicity and more an understanding of cultural states of being. Fisher argues that the "new generation" are working within this discourse and testing limits as opposed to working outside of the mainstream completely (2008: 204). This method exposes "aporias and contradictions of its master narratives. The result was a rejection of the unified or totalizing narrative" (ibid). You have to work within hegemony and play the game to change it (Hall, 1996). What 
this means for Asian New Zealanders is that instead of denying their sense of Asianness they are tapping into both the potential and limits of assuming both Asian and New Zealand identities.

In this context, it is important to consider what unified and totalising narratives achieve. Although these narratives warrant a sense of harmony and connection between groups of people at varying states of inclusion within this settler colony, they can also generalise and undermine the layers of complexity found within specific situations and ethnicities. On the other hand specificity also endorses difference and separation.

Papastergiadis confirms the role of institutions like museums in the "establishment of role and functions that affirm certain forms of identity" (1998: 31). Identity for Papastergiadis opens up to defy the boundaries of institution by evading definition by "one aspect of social life, whether this be sexual orientation, cultural background" because this "confines the very possibility of understanding the multiple ways our identity is enfolded in the lives of others" (1998: 32). He aims towards a representation that is constitutive but not exhaustive of who you are.

Papastergiadis goes on to discuss Bhaba's seminal ideas on hybridity and that it is not a cultural situation that demands integration but a position which "emerges from the tension of the supplement: that appendage which questions the unity of the object to which it is attached" (1998: 43). It is this attachment to a unifying term and concept - being part of an Asian New Zealand rhetoric - which I attempt to unfold in this study. We are past the stage of needing these terms Asian and New Zealand to be mutually exclusive but the focus is now on how this term is manifested in the narratives and lives of people in this "hybrid" state. If there is an element of attachment to either of these cultural statements - Asian and New Zealander - then the dialogue between these two is worthy of investigation. Figuring out these connections and what they are exactly will lead to a better representation. Because museums are held with the task of 
representing people, this research can suggest ways to be responsive to contemporary conceptions of identity making.

Coombes questions the efficacy of asserting hybridity to challenge dominant structures and advocates for strategic essentialism in exhibitions (1998). She says that "often more than not, such exhibitions demonstrate a curious resistance to addressing the implications of such potentially contradictory categories." Arguments proclaiming to vouch for hybridity often undermine the deep and layered complexities in transaction and negotiation (Coombes, 1998).

Demos describes the hybrid as a result of "modernity as exile" (2009: 72). He outlines other conditions resulting from this "exile" as the diasporic, the nomadic, and the refugee (2009). Bourriaud coined the term "relational aesthetics" to describe creative practice which is dependent on human relationships and global networks (2002). ${ }^{14}$ Although he is specifically referring to art practice, his ideas are applicable to hybrids who are essentially tied to an idea of an offshore global identity whilst also being located quite firmly within a certain place and context. The premise of Bourriaud's argument is based on the idea of the international exhibition and networks between people. Bourriaud (2002) puts forth the idea that it is virtually impossible to be unconnected to a global current and that this inevitably effects ideas, information and identities. Both Demos' and Bourriaud's ideas can be applied to the cultural and creative situation of Asian New Zealanders where they are in a position to piece together and create new identities as a result of diaspora, travel, migration and dual identities which have a global lens with local circumstances.

The theory of cosmopolitantism seems like an appropriate expansion on the idea of "modernity as exile" or relational aesthetics. Cosmopolitanism also acknowledges the role of globalisation in producing identities beyond

14 For example he often cites the work of Rikrit Tiravanija, an artist who often stages elaborate events within galleries to look at the social event as a site for participation, interaction and experience. 
borders of nationality and geography (Kendall, Woodward \& Skirbis, 2009). This is also useful within the context of study which aims to go beyond an identity based upon a sign leading to an offshore signifier.

Cosmopolitanism takes a "citizen of the world" approach (2009: 7). However, the theory of cosmopolitanism has its limitations because a degree of knowledge or cultural capital must be attained before being able to be this worldly citizen, "cosmopolitan values involve a set of cultural competencies which enable individuals to see things, participate in or with them, and use them in such ways that they are identified and identifiable as cosmopolitan" (2009: 21). It is not to say that people of dual ethnicity may not already have a degree of cultural competency by virtue of their cultural plurality through education, however, this seems too prescriptive in the idea that travel or adapting to new cultures is made by choice as opposed to necessity.

The literature on identity I have so far presented discusses identity in the context of a globalised, networked world. I do not want to forget the potential significance of this project to a localised context and will attempt to show the potential of Asian New Zealand identities which can be read as hybrid or cosmopolitan or strategically essentialist or otherwise. Outside of Māori and Pākehā, Asians are the oldest group to reside in New Zealand. There are other issues to do with identifying as Asian in New Zealand. We are a group that see ourselves as different from both Māori and Pākehā. Some of the issues of Asian identity within settler colonies are described in Asian Settler Colonialism (Fujikane, 2008) which uses the case study of Asian settlement in Hawaii. In this text Fujikane describes how Asian people within Hawaii do not have the political capacity to colonise but can unknowingly add to the settler agenda and status quo, despite differences in experience and privilege (Fujikane, 2008: 7).

Ip \& Pang (2005) discuss how in New Zealand biculturalism and multiculturalism have been constructed as mutually exclusive concepts and that Asian determination has been read as a new threat to a bicultural 
model. Ip \& Pang believe these concepts should not exist in opposition to each other and that a "bicultural model can accommodate diversity without eroding Māori interest" (2005: 186).

On another local note is Paul Meredith's argument where he applies the term hybrid to a potential third space in the context of biculturalism in Aotearoa. His idea is that hybridity "avoids a politics of polarity between Māori and Pākehā" (Meredith 1998: 4). His idea focuses on "adaptation and transformation of culture and identity predicated within a new inclusive postcolonial Aotearoa/New Zealand community that seeks to reconcile and overcome the embeddedness of past antagonisms" (ibid). Within this model he proposes is possibility for engagement within the new diversity of New Zealand and a new lens to understand and interpret cultural identity.

\section{Representation as both a process and a tool for response}

Hall discusses issues of political positioning within language that maintains an important difference between the norm (white) and 'other' culture (1996). Although Hall focuses his ideas around Britain and the defined categories of race (in terms of colour) his ideas about signifiers and their relationship to historical constructions is easily applicable to Asians in New Zealand. He states that:

Black is not a question of pigmentation. The Black I'm talking about is a historical category, a political category, a cultural category. In our language, at certain historical moments, we have to use the signifier. We have to create an equivalence between how people look and what their histories are. Their histories are in the past, inscribed in their skins. But it is not because of their skins that they are Black in their heads (1991: 53).

If we apply this idea to a New Zealand context, where the 'other' group are Asian people then we can see that the term 'Asian' becomes the embodiment for an experience related to certain ethnic groups. Through Hall's theory then we can see how the term Asian itself has shifted from being an ethnic category to a cultural one. 
Hall believes that representation and the represented are reflexive entities, with the subject capable of having their own response to this representation (Hall, 1997). This idea is echoed by McCarthy (2007) in his study of Māori through museum display which revealed how Māori were active agents in their own representation through exhibition. I have not yet encountered a study of this nature on the representation of Asian people in New Zealand. There have been comprehensive histories of Asian people in New Zealand, and material on the way they have been represented, but I have not found a study where biography and institutional articulation meet within the context of museums as a pathway to understanding this. Grossberg articulates that "identities are always relational, and incomplete, in process" (1996: 89). This theory is suited to understanding the identities of Asian New Zealanders whose identities change and fluctuate depending on situation and circumstance.

I use the terms Asian and New Zealander as reference points and starting places, not as end points. The problem with trying to arrive at the underlying criteria of a disparate and confused term like 'Asian' is in reverting back to an essentialist notion of what that term means. Grossberg acknowledges this difficulty in identity politics and suggests that adopting a certain identity in lieu of another has been used as a strategy (1996: 89).

Grossberg says that the new struggle "over identity no longer involves questions of adequacy or distortion, but of the politics of representation itself" (1996: 90). He suggests an examination of "how identities are produced and taken up through practices of representation" (ibid).

These practices include how you represent yourself though speech and action and how you are represented through the public institution. Hall theorises that "the representation of 'difference' through the body became the discursive site through which much of this 'racialized knowledge' was produced and circulated" (1997:244). If we take Hall's idea that meaning is imposed and part of a discursive formation (1997:56), then the hybrid is 
allowed to be both part of a strategic political positioning and to defy it. Hall states that:

Individuals may differ as to their social class, gendered, 'racial' and ethnic characteristics (among other factors), but they will not be able to take meaning until they have identified with those positions which the discourse constructs, subjected themselves to its rules, and hence become the subjects of its power/knowledge (Hall 1997:56).

Hall's writings on representation reveal how Foucauldian ideas about regimes of truth inevitably effect the process of representation because of the way signs and language operate within these regimes to produce a representational product (1997). The above quote suggests that Hall advocates for working within the paradigm in order to rewrite it. Denying contained categorisations such as 'Asian' would mean disappearing into a zone of indistinction without a sense of voice.

Lidchi discusses the politics and poetics of exhibition practice and how museum displays are inevitably involved in regimes of power. She describes how museums make certain cultures visible but also subject them "to the scrutiny of power" (1997: 198). Although this is true, despite the museum's ethnographic tendency, inclusion within a national display such as at Te Papa means that a group is part of the national narrative and has access to that regime of power. Te Papa has also handed some power over to the groups it represents through community consultation and their involvement in exhibition making (Ballard, 2005; Gibson, 2005).

Lidchi talks about the layers of representation within display and how denotation refers to an initial layer of meaning where representation "derives from a descriptive relationship, between signifier and signified, corresponding to the most obvious and consensual level at which objects mean something" (1997: 164). The second, more conceptual layer of meaning is connotation "which guides one to look at the way in which the image (object) is understood, at a broader, more associative, level of meaning" (ibid). 
Museums, through display, are inevitably involved in both processes. An idea, image or object seems to be easiest to manipulate at this denotative level within an exhibition context. It is important to remember that visitors go to museums with their own sense of connotative meanings and do not enter as a blank slate (Hooper-Greenhill, 2006; Mason, 2005; Newman, 2005; Sandell 2007). Nothing exists outside of representation, it is always something we sit relative to and contribute to whilst also having it contribute to how we construct ourselves. Representation is always mobile, never static, neither are identities. There are also stages of representation which relate to us in a macro and micro way (levels of denotation and connotation). Although we may be disconnected to the micro level representation we see through museum exhibition, because of the political site it rests on, the macro level of representation tells us something about ourselves, and where we stand within the nation.

\section{Summary}

Our sense of belonging not only relates to the social makeup of the interactive, human relationships we have but is also invariably shaped by our history beyond ourselves, and our representational history which deems the way we are understood within the place we live. This representation has been contentious partly because of the way Asians have been constructed in this country, as polar to the ideal idea of a New Zealand citizen. Although culturally this idea can mould and mutate, part of this sense of difference is upheld because of the way we look and that we stand as a signifier with meaning beyond our control. Museums have adapted the categorizations imposed on people as a strategy of inclusivity. Museums are also political spaces where notions of risk are heightened because of their connection to public consciousness.

Contemporary identity theory has attempted to create ideas that are more responsive to the way citizens might understand or organise themselves beyond archaic limitations of race and ethnicity. I want to avoid these theories as merely another tool in determining how people feel and think. 
Because museums are in the task of creating and communicating representation, this research is useful to understand a longitudinal approach to representation which precedes and succeeds the encounter with the exhibition. This research is useful within the field of Museum \& Heritage Studies because it takes a broad, conceptual approach to the cause and effect process of representation through exhibition in the public arena of the museum.

This chapter has charted the main issues of concern that this dissertation addresses: the nature of the representation and identity of Asians in New Zealand and the representational processes that both the museum and people use when creating identities. I have shown the current situation and routes for further discussion.

Chapter 2 will be an explanation of the methodological approach of this research. I start chapter 3 with an analysis of Passports and the participants' reactions to this exhibition. This sets the ground for the departure of differing conceptions of identity. Chapter 4 looks at how the participants construct their identities and how they arrive at their multiple identities through the institution and through their own thinking. Chapter 5 builds on the previous chapter and looks at the way multiple identities are negotiated within the participants' positions and perspectives and provides clues for future ways of thinking about representation. Chapter 6 will be a conclusion of thoughts attained from the analysis and suggest an alternative to the way ethnicity and identity is currently experienced and articulated through museum exhibition. I also determine whether or not identity theories aid in the articulation of cultural situations. It is hoped that this dissertation will demonstrate the reflexive nature of both representation and encounter, as well as the ways in which we try to connect to each other, beyond ethnicity, towards a common place. 


\section{Chapter 2: Methodology}

\section{Introduction}

In order to comprehend how people understand themselves, the best approach is to look at their narrative biography. Identity theories have been discussed in the previous chapter but these theories have been understudied empirically. Through understanding the construction of identity and the methods the participants use to represent themselves, the museum can better gauge their relationship to identity making and social inclusion, leading to better representation. This research began through questioning how the museum represents national identity. Who is included in that identity? How are Asian New Zealanders represented in current practice? What influences Asian New Zealanders sense of identity making? Te Papa opened in 1998, with Passports as one of their opening exhibitions (Waite, 2009: 53). I was curious to see how identity politics have changed since Te Papa's opening.

This research investigates the way identity and representation is constructed through both the museum and Asian New Zealanders' narrative biographies. These two sides to representation are considered in order to make comparisons and to investigate the relationship between the representation of how people construct their own stories and how this is articulated on the exhibition floor. I am also trying to show how this relationship between museum and audience has an effect on feelings of belonging going beyond the museum's walls. The person's story is considered the 'source' of identity making, while the exhibition I determine as a 'product.'

The primary source of empirical material for my research was narrative interviews with people who related to the term Asian New Zealander. Narrative interviewing provides valuable information to understand the way identity is constructed because of the way "a sense of social order is created through talk and interaction" (Elliot, 2005: 18). It also makes sense 
to use this method because my focus is less on the idea of identity and representation as an external reality but rather "that the social world is constantly 'in the making' and therefore the emphasis is on understanding the production of that social world" (ibid).

This chapter charts the rationale for adopting a narrative approach for this study, outlines the interview methods used, discusses ethical issues and gives a brief introduction to the participants.

\section{Rationale}

The role of narratives is particularly applicable to my research because “they provide insight into individuals' experiences and the meaning they make from them," and they tell us "something about the cultural framework within which individuals make sense of their lives" (Elliot, 2005: 28). The narratives therefore serve a two-fold purpose, as they speak about personally articulated meanings and wider cultural meanings.

I have selected this research method because I am primarily interested in the reflexive process of representation, and the ways in which subjects respond to their own external representation (Hall, 1997; McCarthy, 2007). Hall sees the process in identity formation as involving "resources" which are encountered, reacted against or embraced (1997). According to Stivers, we create identity and meaning through stories as "a result of the stories we tell about ourselves or that others tell about us" (2009: 177).

Te Papa has also taken a narrative approach to Passports by using personal stories to illustrate its theme of migration and settlement in New Zealand (Te Papa, 1996). This reflects a wider shift within ideas surrounding the new museology, moving away from relying solely on an object based approach and looking at polyvocality and personal stories to stir empathy and to convey an idea (Pieterse, 2005).

Because of my personal connection to the subject of this study, I am positioned both epistemologically as well as subjectively within the text (Denzin, 1989: 34). I do this by using personal pronouns and by speaking 
as an affiliate to the participants. Narrative biographies also provide valuable information on the wider social implications of the identity construction because:

Biographies cannot simply be the products of individual agency... people have to be hugely creative in order to salvage agency and personal narratives in a global world that often moves with a momentum beyond their individual control (Burkitt 2009: 226).

The interview material shows the relationship between these personal narratives and the wider social world, in this case the museum in its role of representing public history.

The narratives were in response to the stimulus of the museum exhibition Passports because in terms of interpretive strategies, and the epistemology of my dissertation, "concrete, contextual biographical materials are gathered via the use of the narrative interviewing strategy which involved a subject responding to stimulus, i.e. recounting a set of life experiences in the form of a story of narrative" (Denzin 1989: 56). This idea also complies with the new museology in understanding visitors as active participants in the process of meaning making and not solely as passive observers who are objective to the information they receive within a museum context (Hooper-Greenhill 2006: 362). A focus on the realisation that visitors are interpreters, shows how museum visitors also contribute to this process of social construction of identity making.

The interviews were conducted in an attempt to hear about "personal experience narratives" where the "focus is on shareable experience. Personal narratives are more likely to be based on the anecdotal, everyday, commonplace experiences" (Denzin, 1989: 44).

The narrative interviews are looked at in terms of "hegemonic tales" in order to look at social structures taken to be as social norms or truths (Elliot, 2005: 146). Elliot describes hegemonic tales as "those ideas, power differentials, and structural arrangements that are so securely embedded in the social fabric that they literally 'go without saying'” (2005: 146). Looking 
at this type of information becomes particularly relevant when examining ideas about the exhibitionary order and integration of Asian groups within the national story.

\section{The interviews}

I interviewed five participants who ranged in age from 21 to $46 .{ }^{15}$ The participants came from a range of backgrounds but unfortunately I was unable to recruit anyone who was a $3^{\text {rd }}$ generation Asian New Zealander. A larger sample would have been desirable, but due to the constraints of the scope of this dissertation, five was considered a sufficient number. I tried to obtain as diverse a range of Asian ethnicities as possible, as well as a gender balance. I interviewed 3 females and 2 males. The ethnic diversity of the sample is discussed in the section below on the participants.

I chose to interview people I had pre-existing relationships with. This was important because of the personal nature of the subject matter discussed. Because the participants all knew me well and trusted me, they were more open and honest about their stories and saw me as an "insider" not merely a researcher. The only minor limitation with this relationship was that sometimes the participants skipped finer details because of my prior knowledge of their lives. However the benefit of this was that there were implied meanings that emerged as well because the participants rightly assumed that I shared similar experiences to them. Phrases such as "you know" suggested the relationship I shared with the participants, as informed, empathetic, and one of them. This also placed a good level of ethical responsibility on my part to respectfully portray the sentiments of the participants throughout the analysis chapters.

The first stage of the interview consisted of a museum visit to Passports with the participants. This visit varied in length according to each participant, however, the average time spent in the space was ten minutes. After viewing the exhibition visit we sat down at the Level 4 café where I

\footnotetext{
15 Ethical approval was obtained from Victoria University of Wellington Ethics Committee for the interviews.
} 
explained to the participants: "I would like you to tell me about your sense of belonging in New Zealand. Perhaps we can start with the exhibition, is there any material you connect to in terms of your own life?" This acted as an open ended question with minimal prompting where required. This part of the interview also varied in length but on average took 15 minutes at least and one hour and a half at most.

The second part of the interview was undertaken between two days and a week after the first interview, dependant on participant availability. The second interview was conducted away from the museum and was moderately structured (Wengraf, 2001:152-182). Questions asking the participant to divulge their personal experiences were constructed in regards to their responses from the first interview. The interviews were then transcribed verbatim.

Denzin's ideas on interpretative strategies where interviewers "prompt subjects to expand on various sections of their stories" and "respondents are next asked to theorize about their lives" (Denzin, 1989: 56) were used for the second interview. I used Wengraf's lightly structured depth interview (2001: 111-152) as well as his research design of moderately or heavily structured interviews (2001: 152-182) to construct a two stage interview. Two interviews were undertaken because the first was a reactionary account of the exhibition and loosely structured in regards to their own histories whilst the second interview allowed the participants to think about answers they had given and gave them an opportunity to theorise their identities.

Passports was selected because of the range of ethnicities displayed in the exhibition and because it is intended to represent Tangata Tiriti in Te Papa. Passports will be further discussed in Chapter 3. It is not too focused on a particular ethnicity and ambiguous enough so it allows for the participants to engage with the different communities on display. 


\section{The participants}

In this section I introduce the participants through their own words. It feels appropriate, that within the context and ideals of this study they are given the opportunity to articulate their own heritage as opposed to letting a researcher categorise them.

To retain the ethical integrity of this research, participants were consulted about their answers and amendments and pseudonyms have been used as necessary. The underlying philosophy of this research is to value the voices and stories of people and not over theorise them according to other people's ideas. This approach is taken throughout the next three findings chapters where I attempt to let the people speak for themselves.

To honor the stories, I have tried to put them in the context of the surrounding ideas in which they were said instead of reducing quotes to mere sentences. It is unreasonable for me to dissect the words of the participants into categories when this study in itself is aiming towards the understanding of people and ethnicity as evading categories. Throughout the analysis words used by the participants are italicized. I have edited out conversation fillers but have tried to remain true to their stories by using only their words. ${ }^{16}$ Some sentences have been adjusted for coherency. Appendix 3 is a transcript from one of the interviews so the reader can understand how the interviews were constructed and material was interpreted. My own position is as a New Zealand born Asian New Zealander of Cambodian and Indonesian parentage and it is through this lens in which I affiliate with the participants, through shared ethnicity and experience.

$\underline{\text { Alan }}$

I was born in New Zealand in Palmerston North. How we got to Palmerston North is my parents grew up during the Vietnam war, so obviously I've got Vietnamese heritage there. The heritage is Chinese but obviously they were living in Vietnam.

16 Such as "um," “ahhh,” “like," “I don't know." 
Anna

I think it's kind of cool to tell people that you're half Japanese and half Pakistani 'cause I've never met anyone with the same combination...I do still want to maintain that.

Bernice

As you know I was born in a Pacific country, Fiji, and I have Indian ethnicity... I mean I was quite young when my family migrated here and we migrated because of the coup. That was a huge upheaval for my family and a lot of other families, and I mean the choices my parents made have affected me but I was so young when I came here that I kind of feel that a part of my childhood has been left in another place.

$\underline{\text { Charles }}$

Well, I feel connected to the migrant story in general in a broad context because I came here when I was 12. My father is a New Zealander, he was born in Hawkes Bay and he's Pākehā. And my mother is Indonesian Chinese. I was born in Kuala Lumpur in 1964, we came here in the late 70 s.

$\underline{\text { Sarah }}$

So we're from Cambodia. My parents are from Cambodia. I think maybe my great, great grandfather was maybe Chinese so we have Chinese blood in us but I consider myself probably full Cambodian and the reason why we are in New Zealand is because of the war in Cambodia and the Khmer Rouge and Pol Pot... And I think that's what shaped me a lot as well like even though I didn't go through their hardship, it's something I'll always go through in the back of my mind.

\section{Analysis}

The narrative interviews were examined for "hegemonic tales" (Elliot, 2005: 146). Analysing the empirical material in this way is particularly relevant when examining ideas about the exhibitionary order and the integration of Asian groups within the national story.

The analytical technique used was Pamphilon's "zoom model" where "the methodology acknowledges and indeed maximises the multiple and potentially contradictory perspectives within any one life history" (1999: 395). This method is appropriate with the vexed construction of identity evident in the interviews as well as the different positions participants 
adopted at points during their stories in relation to ideas about self and other.

Pamphilon discusses four levels within the zoom model but for my study I focused on the macro, meso and interactional. ${ }^{17}$ For the purposes of understanding the relationship between people's stories and the contributing environmental factors they exist in, the macro zoom lens looks for the "dominant discourses, seeking to understand the cultural prescriptions of the time," from this the macro zoom analysis "can reveal the variable impact of historical events on the lives of individuals by illuminating cohort similarities and differences" (Pamphilon, 1999: 395).

Within this study, this relationship focuses on the interaction between the participant, identity and representation within the parameters of the sociopolitics of New Zealand. This allows the analysis to primarily focus on the individual's life story without being laden by theory, but being aware of the "sociocultural dimensions [that] stand in the background for consideration and possible refocus" (ibid).

The meso zoom reveals "themes that have been constructed by the individual in order to forge a coherency across her life history" (Pamphilon, 1999: 396). The narratives are discussed in terms of their main themes and ideas in order to explore whether or not there is a communal experience and how the participants theorise about their lives and cultural situations.

Finally the interactional zoom fulfils the aim of study to be autoethnographic in that it "asks the researcher to overtly acknowledge and zoom into their own place in the research whole" (ibid). This will also make apparent my interpretation of the narratives which are overall shaped by my research aims. I do this by affiliating with the participants with markers like 'we' and by carrying an ethical responsibility to have their best

17 Pamphilon outlines the macro, meso, micro and interactional lenses in the zoom model method of analysis (1999). The micro zoom focuses on the 'oral dimension of the life story' to include the emotional aspect of story telling including pauses and absences in narrative. Although this will be considered and included where appropriate the analysis of ways of talking is not my main focus. 
interests at heart because of my position as not only a researcher but as having a relationship with the participants outside of this research. I insert myself into the research at the appropriate time by speaking directly as a listener and reporter on the participants words. However, I also let the participants speak on behalf of my own sentiments and take a distanced role when discussing the analysis chapters. Pamphilon emphasises that the 'researcher's interpretative role is an active one at every point as he or she chooses what to elicit, highlight, and make visible" (ibid).

For the purposes of this study I place the museum at the macro zoom level and the interviews in the meso and interactional lens. Experiences and feelings from the museum visit act as a filter between the two. Keeping the museum in mind, these interviews always had the overarching idea of representation at the core of the issue with the visit and subsequent narrative as an example of what emerges from a person's encounter with an exhibition.

Alongside the analysis of the narrative interviews I have included some theory where this aids the interpretation of the primary source material, but otherwise I have attempted to let the stories speak for themselves. Concept development plans for both Passports and the community gallery exhibitions were also analysed and are discussed in Chapter 3.

For clarity and logic, I have organized the findings chapters to represent a progressive narrative. In Chapter 3 I start at the beginning of the interview where participants react to Passports to show their position in relation to the material on display. Chapter 4 discusses the formative years of identity making, where the participants generally started with realising the idea of difference and their own difference in relation to those around them fostered in school environments. This chapter also looks at how they construct their own sense of selves in relation to this difference and some of the initial ideas about being Asian and being a New Zealander. Chapter 5 introduces the idea of affinity and what constitutes the Asian New Zealand experience. This chapter also reveals how participants navigate and 
negotiate multiple identities and how they counteract prescribed ones. The end of Chapter 5 also reflects both the content and sentiment of the end of the narrative interview material. 


\section{Chapter 3: Reacting}

\section{Introduction}

The remarkable realism of such displays made the Orient into an object the visitor could almost touch. Yet to the observing eye, surrounded by the display but excluded from it by the status of visitor, it remained a mere representation, the picture of some further reality. Thus, two parallel pairs of distinctions were maintained, between the visitor and the exhibition and between the exhibit and what it expressed. The representation seemed set apart from the political reality it claimed to portray as the observing mind seems set apart from what it observes (Mitchell, 1998: 462).

In the above description Timothy Mitchell argues that the construction of the exhibition, in his particular case, the $19^{\text {th }}$ Century World Fair, is a reflection not of the culture represented but rather how the exhibitor articulates and constructs other cultures. Preziosi describes Mitchell's argument as a desire for reality behind representations, "a desire that is forever unsatisfied" (1998: 425).

Preziosi draws attention to the limitations of being "represented" because our identities are never complete and always in process (Hall, 1997; Grossberg, 1991). Although our relationship to representation alters depending on our subjectivities and positioning, the process of reacting to seeing ourselves is standard in the sense it is always one of reaction and affirmation or rejection (Hall, 1997).

This chapter reveals how the ties between the participants and New Zealand is engrained. Despite the fluidity of identity making and contradictory positions taken, they remain connected to being New Zealanders. What was up for negotiation was the projected Asian identity being exhibited. The participants looked at this through a mediated vacuum of what it means to be an Asian New Zealander. The museum acted as one of those intermediaries through which the participants compared their own sense of identity with what the museum presented as Asian New Zealand experiences. The museum thus became a place not of connection but of response. 
This chapter analyses the reaction of participants to Passports - an exhibition of New Zealand immigrant history at Te Papa that opened in 1998. ${ }^{18}$ I provide a brief overview of the structure of the exhibition and outline its aims and objectives. By examining the relationship between the representations in the exhibition and the direct responses from the constituents it represents, I will directly join two ends of Hall's circuit of culture diagram through this juxtaposition (Appendix 1).

\section{Reacting to representation}

In the remainder of this dissertation I discuss the origins of "being" and "becoming" in the lives of the participants. This will be presented through the themes and ideas that arose during the course of the interviews. Although the stories diverge in terms of their specific details, I found that there were commonalities in the type of significant events that shaped identity making, and the pattern of the structure of the narratives given by the participants.

For each participant, the initial interview was conducted at the site of Te Papa after a visit to the exhibition Passports. The visit was included not only to act as a catalyst for thinking about and talking about identity with the participants but also as a way to see how concepts of identity are enacted, resisted and relative to the identities of the participants. What emerged in the space between the participants and the exhibition was a third space of encounter between representation and represented. ${ }^{19}$ After reacting to the exhibition all the participants began their stories citing examples where they were alerted to their sense of difference and had their New Zealand identity challenged.

The participants were conscious of the fact that the exhibition was meant to exemplify and represent the different peoples of New Zealand, this was

\footnotetext{
18 http://www.tepapa.govt.nz/AboutUs/history/Pages/default.aspx

19 Paul Meredith considers this space hybrid taking a cue from Homi Bhabha's ideas about the third space and hybridity (1998: 2).
} 
despite the limitations in the range of people/ethnicities represented and the exhibition space allocated.

\section{Passports}

Passports is situated on Level 4 of Te Papa in between the Community Gallery and Signs of a nation. Signs of a nation is largely abstract in its presentation with few objects ${ }^{20}$. Apart from facsimiles of the treaty itself, the key interpretive device features multiple voices expressing differing views about the Treaty of Waitangi. The focus within Passports is more oriented towards objects and the personal stories that go with them. It is an exhibition that is the embodiment of the new museology: polyvocal, experiential, emotional and aiming for social harmony (Stam, 2005). Te Papa says

Passports explores and celebrates the remarkable stories of the people who migrated to New Zealand. Focusing on all nationalities other than Māori, this exhibition presents the objects and ideas the migrants brought with them and examines how they adjusted to the new land (Te Papa). ${ }^{21}$

There is an ethnically diverse group of people represented within Passports and the exhibition "uses a thematic approach - leaving, travelling and arriving. These themes of leaving familiar surroundings and moving into uncertain territory allow people of all ages to identify with the migrant experience" (Te Papa Concept Plans 1996). In this context all ethnicities (apart from Māori) are considered immigrants. The exhibition uses a combination of text, sound, objects, interactives and film to achieve the aims of this story.

As you walk into the exhibition space you are greeted with piles of suitcases and a passport issuing machine. It is a multi sensory experience with a combination of objects within arms reach through drawers that visitors can pull out and look into and objects revered beneath dim lighting

20 These objects are largely historical, centred around the idea of voting and law such as a barrister's wig and a ballot box.

21 http://www.tepapa.govt.nz/WhatsOn/exhibitions/Pages/Passports.aspx 
and elevated plinth panels. Passports is divided into three thematic sections; "life back in the mother country (Leaving the Homeland), the journey to New Zealand (Crossings) and the arrival in a new land ( $A$ New Country)" (Waite, 2009: 60).

There is an interactive display people can engage within the main space. It asks you to imagine being in Britain and asks a series of questions by pressing buttons to ascertain whether or not you would be a desirable candidate for citizenship to New Zealand in the $19^{\text {th }}$ century. Nowhere in this interactive does the issue of race arise excluding a negative but albeit important aspect of New Zealand's history. The exhibition instead focuses on the endurance of settlement in creating what New Zealand is today.

There are also many choices of routes the visitor can take within the exhibition. An access point through Passports leads visitors to the Community Gallery. From the 'cabin' the visitor can then either view a film or go on to spaces within the theme of A New Country, this is divided up into different ethnic groups and families through themes such as religion, food and sport. There is a heavy emphasis on European histories of immigration and the tales of people's experiences from that geographical perspective (Waite, 2009: 62). There is, however, one section dedicated to the $19^{\text {th }}$ century Chinese immigrants and in particular the gold miners of the Guangdong province. It was envisaged that communities who did not have a strong presence in the Passports exhibition would be showcased through the adjacent community gallery (Ballard, 2005). Passports takes a historical approach to the idea of immigration and places emphasis on subjective stories (Waite, 2009: 61).

Objects on display show everyday items such as cooking utensils and religious artefacts aiming towards familiar and recognisable items as opposed to offering the visitor any epiphany or encounter with something new. Passports is focused on showing experiences of people on the premise of immigration and arrival and takes a broad approach to ethnicity by connecting it back to a country of origin. 
Foucault describes heterotopias as spaces where different variants of time converge; past, present and future are all ambiguously arranged so that they all simultaneously exist (2004). An exhibition like Passports is an example of this heterotopia because the emphasis of this timeline is secondary to an arrangement through themes. The exhibition also show an ideal arrangement of different groups and ideas co-existing comfortably within the same space, also aligning with Foucault's ideas of the heterotopic space (2004).

Participants' criticism of Passports related to the size of the exhibition and the lack of connection the participants felt between themselves and the themes on display. The participants felt the exhibition was dated and that it no longer represented who they were. The emphasis in their personal stories was not on migration or arrival but rather being here, attempting to feel settled, and negotiating their multiple identities.

\section{Responses to Passports}

In their interviews, and to varying degrees, the participants used the exhibition as a catalyst for telling their stories about identity and belonging in New Zealand. Some were more critical than others. The object centred approach of Passports attracted the most interaction as opposed to reading the text panels or using the interactives. On average, the participants spent very little time within the exhibition and were more reflective about the exhibition once we sat down for the interview away from the space. ${ }^{22}$

The most connected response to the exhibition was on a conceptual level between Sarah and her experience of seeing the section on the $19^{\text {th }}$ century Chinese gold miners.

When we were there I saw the goldmine part, and not just because the photo was of people of Asian descent, but also I just kind of thought that the people that come here are the people that really work and really work hard to make a living for themselves, and just to provide for their

\footnotetext{
22 On average 10 minutes was spent in the space and sitting down for the initial interview took around an hour and a half at most and 40 minutes at least.
} 
children and have a better life than they would where we're from, Cambodia. So I guess that's how it related to me the most in the exhibition, and I guess that's how we kind of had a sense of belonging in New Zealand, being a part of New Zealand was by working hard. It's just always been a part of our lives cause we didn't come here out of choice really. It's because we had to, well not me but my parents, to have a better life to get away from the war and things like that. The only way that they could really belong was to work.

(Sarah)

Sarah relates to the exhibition narrative on a personal level through her shared ethnicity with the migrants on display and through relating to the experiences that they endured which were similar to her parents' story of settlement in New Zealand.

Like Sarah, all the participants actively sought to see how they were represented in the exhibition, and this was done by way of affiliating through ethnicity. They all tried to look for their ethnic group upon entering the space and were less concerned about connecting to a New Zealand identity but rather saw the array of different ethnicities on display to seek another aspect of their identity represented. Once they found their community on display they expressed distance from the experiences represented.

The size of the space was considered small. A common remark made by participants whilst walking through the exhibition space was "is this it?" They expected an exhibition of such an important topic within a national museum to be much larger and to see themselves represented in a much more insightful manner.

Charles related to the experiential and conceptual ideas of the exhibition such as connecting to
...The story of the Chinese migrants to New Zealand and other groups particularly from South East Asia I've grown to really identify with... I like the real minority stories... I guess I probably identify more with the non Anglo Saxon diaspora in New Zealand, and I like the stories of the Greek New Zealanders and those European minority groups that came to New Zealand. 
Here Charles does not limit his feelings of affinity to the ethnicities on display but rather understands the connections he can make to a collective experience that the non Anglo Saxon diaspora face when moving to New Zealand. However Charles questioned what the underlying agenda of Passports was. When I asked if Charles felt adequately represented by Passports he said

Not by Passports, not at all. It's just too small. I think that this must be a common complaint amongst all the minority migrant groups that are represented by Passports. It really does pay lip service I think to the demographic reality in New Zealand today.

In response to the objects in Passports, Alan said

In terms of the exhibition...I think it might be a little bit geared towards the colonial side isn't it? Maybe not to the recent aspects which include my parents. My parents' generation weren't really part of that exhibition. Although I would have felt more of an affinity towards the European stuff just because that's what you grow up with. You go around understanding the European side of culture so when I saw the mandolins and everything I didn't really know what that was about or really know what was going on.

(Alan)

Conversely, Alan connects more to the European stuff, which was surprising as it poses the question of what we connect to. Do we connect through national cultural symbols or ones imposed on us through ethnic affiliation? Interestingly, the conundrum Alan presents here with his response highlights the limitations of material culture in soliciting a sense of cultural affinity from visitors. The objects on display in Passports for the Chinese gold miners section include Chinese ceramic bowls, jade ornaments and flat spoons. These objects essentialise notions of Chinese "culture" and "ethnicity" to the extent where connecting to this culture is exemplified by a connection to these objects. The objects become a stand in for the experience of cultural affinity. In terms of migration history and the settlement of Asian people in New Zealand, part of the emotional distance created from the originating cultural land is from the dislocation of these objects in their new found home. However, the notion of ethnicity is experiential which goes beyond material culture as a reference point. 
Bernice's words demonstrate the subjectivity of that connection. Because her country of origin is in the Pacific, she finds greater connection with those signs and symbols than with the Indian material on display. There is a disjuncture between ethnic affiliations and national sentiments. Bernice saw the exhibition as a separation between herself and the older more established settlers to New Zealand.

I wouldn't connect to it because I wasn't born of that ethnicity that those people settled at. They have their own traditions and I had my own traditions when I moved here... Personally I would relate more to the Pacific area than I would with the settlers, early settlers or even with the Asian immigrant settlers as well. But that's a personal thing.

Interactions with representation are always relative to our own connection and understanding.

Early on in her narrative, Anna made a distinction between the idea of being from here by birth and migrating here.

I personally thought that exhibition was more about Màori and European heritage... I guess in that sense I didn't really feel a connection... I think cause I was born here I do have that connection and maybe it's a lot different if maybe you're an immigrant. I feel that cause I was brought up here I do feel like a New Zealander. I would actually call myself a New Zealander rather than an Asian or something else.

(Anna)

Although Anna did not connect to Passports through her ethnicity, she also failed to connect to the exhibition on an experiential level because of the focus on migration. A problem with the ethnic specific, object centered and story approach Passports has taken is that it sets a measure for comparison to the visitor's own personal history. Because Passports focuses on migration, there is an automatic disjuncture between the situation of the participants and the situations of the people on display. Within the interviews the participants were affirmative in who they are as New Zealanders, this was not a questioned aspect of their identity in terms of their own representation. 
This analysis reveals how the participants can move beyond the idea of immigration, with some of them never having had to physically immigrate themselves. Although they share a history of immigration and difference through the politics of their own ethnicity and cultural category, Asian, their focus is not on travel, immigration or 'going back' but rather about the experiences of being here, in this time and place and the implications of negotiating multiple identities. These identities are not solely ethnically or culturally based, they are also generational and personal. However, in Hall's circuit of culture, nothing exists outside of the intersection between culture, representation and identity building showing that although the participants felt disconnected from the material on display in Passports, this material has a relationship with how they construct themselves (1996). These are all relational aspects to ideas about belonging and identity making.

\section{Summary}

These introductions to the stories of the participants reveal not only where they 'come from' in terms of their own histories of immigration via their parents, but also reveals a number of different of identities that they are invested in. These include their status as New Zealand residents, their parents' heritages and the way these intersect and collide. The above interview excerpts were the beginning of their narratives and firmly show who the participants think they are in terms of their identity and their reaction to their own representation on the exhibition floor. What emerged between the participants and their projected representation was an activated space (Love, 2005) between stories which they were supposed to relate to and the disparity between this and their own lives.

In the quote I began this chapter with, Mitchell (1998) describes the disjuncture between representation and being represented. In the case of social history exhibitions there is a responsibility to accurately convey the thoughts and emotions of the represented subject. This also conforms to Te Papa's aims within their mission statement. The exhibition becomes a 
metaphor not only of a world, but of a world-view where a power dynamic is exerted.

Love's activated space is a desire for an exhibition experience which privileges the feeling of "when you are mixed up, in real time, in the business of making sense of the world as it makes sense of you, which... makes you feel like you might be able to mobilize meanings which hold you rather than remain fixed" (2006: 171). The participants are suspended in this space between seeing themselves and creating themselves.

From the reaction of the participants we can see that the distance created within Passports from what Mitchell calls a "political reality" of the world the participants exist in (1998: 442). The picture of the "further reality" between exhibition and exhibited subject are not in sync (ibid). Real time is collapsed and distance is created. In the case of the participants, they are the visiting observing minds, set apart from what Te Papa observes Asian identity in New Zealand to be.

This chapter considered the idea of reacting to a prescribed identity via the exhibition. The next chapter will be a more in depth look at their own processes of "being" and "becoming" and the ways the participants have constructed and arrived at their current identities. By examining these processes, we can understand how Asian New Zealanders construct their own representation in relation to the museum when it considers them as the subject. 


\section{Chapter 4: Constructing}

\section{Introduction}

It's quite hard because when your parents are from different countries it's like you don't know who you belong to cause I'll go to Japan and I don't even look Japanese. They'll ask you where you're from and I'll say "from New Zealand" ...Or I'll go to Pakistan and they all think I'm Chinese they'll be like "oh are you Chinese?" Or "are you from Thailand?" ... So in that sense it's much easier to say I'm a New Zealander rather than explaining it each time.

Though they seem to invoke an origin in a historical past with which they continue to correspond, actually identities are about questions of using resources of history, language and culture in the process of becoming rather than being: not 'who we are' or 'where we came from', so much as what we might become, how we have been represented and how that bears on how we might represent ourselves. Identities are therefore constituted within, not outside representation. (Hall, 1996: 4)

Hall's idea of how we construct our lives and this relationship to identity resources alludes to the ambiguous process of identity making, that we forage from existing cultural resources in relation to our own ideas. Interviewing the participants, and reflecting on my own position I realise the cyclic nature of representation, how we react yet confirm it, and hold constantly contradictory positions in regards to our positions and feelings.

The opening quotes intersect each other. They reveal the ambiguous way identities are created, deconstructed and reconstructed (Grossberg, 1996; Hall, 1996; Hooper-Greenhill, 1996). Hall's idea looks at the tangible aspects of this process through history, language and culture. Essentially the signifiers that we can see, agree and dispute according to our own personal sensibilities.

The first quote is an excerpt from Anna's story. While Hall touches on the things we can see and touch as a marker of making ourselves, Anna alludes to the intangible aspects of identity making; that it is intuitive and responsive. Her experience is described as a feeling and, although she touched upon physical markers, she also went beyond that to describe 
something visceral and unconnected to signs and signifiers. Anna's words also point to the vexed nature of the representational encounter for many Asian New Zealanders with the question "where are you from?" Her response is both practical but also an inherently emotional response.

Hall emphasises cultural conditioning and how this is theoretically created from socio-political circumstances (Hall, 1996; Meredith, 1998). Although theorists hypothesise the way identities are made, theory does not account for the way we are made to feel, devoid of reading or thinking about theory. It is important not to overlook actual lived experience.

This chapter builds on the previous chapter and focuses on the stories of the participants and the processes by which they construct their understanding of Asianness and New Zealandness and the impact this has on their feelings of belonging. Their first experiences of realising they are Asian and the implicit role this has played in how they construct their identities is also discussed. This chapter reveals the mediated process of 'arriving' at their identity and how cultural resources are enacted and resisted relative to their own sense of being and belonging.

There is a reflexive relationship between a prescribed identity and the idea of creating yourself, independent of those prescriptions. However, instead of having a completely autonomous identity, what is seen in the interviews is that these identities are constituted from a bricolage of sources, some self-determined and others guided by feelings governed by an external prescription through either people or institutions. What is also revealed is the specificity of Asian identity created through conditions in New Zealand. These identities reveal the circumstances of creating your own sense of belonging. Exposing this process of identity making through the participants can provide a point of comparison for the way museums exhibit national identity.

This process aims to determine how identity politics cannot be tied down to specific categories or theories, but rather slips in and out of these ideas depending on situation and context. The museum representation stands as 
something fixed and unchangeable against identities which are fluid, relative and relational.

Bourriaud (2002) suggests the theory of relational aesthetics, in regards to artistic practice, and emphasises how creative products are never isolated from global networks and subjective, human transactions. To this I suggest adding the idea of relational identities with a similar premise of a global lens with local circumstances based on human and institutional relationships. The idea that identities are built upon a wealth of resources defined interpersonally and institutionally shows how identities are shaped relative and relational to these resources (Demos, 2009). The participants assemble a plethora of ideas about being Asian from a multitude of sources. Some come from prescribed ideas about Asianness and New Zealandness while also being connected to their own experiences and are left with sentiments and ideas that are neither specifically Asian nor New Zealand.

What became evident during the process of storytelling was that all the participants had a similar pattern of discovering their sense of being Asian and sense of belonging. Although this differed in process, there still seemed to be a unified sense of experience in terms of when a feeling of being different was discovered and the ramifications of this for identity making. This feeling of incompatibility with the projected representation matched their initial encounters with Passports at Te Papa.

The previous chapter showed how the participants reacted to the question of identity making. This chapter will reveal how this assurance in their identity as New Zealanders is challenged. This chapter charts how the participants try to arrive at a universal identity of being a New Zealander through their own specificities. I have chosen to show this through the first halves of their narrative interviews. Here the participants talked about their formative years in terms of identity making. They discussed how this shaped their sense of perspective in relation to other New Zealanders and to ideas about being Asian. 


\section{Being the same but different}

It became evident there were contradictory and changing ideas that developed within the interviews between intrinsic forms of identity and cultural constructions of Asianness and New Zealandness. The idea of identity as understood by Saukko is the process of confirming, reacting against, or universalising identities and are looked at in terms of legitimizing identities, resistant identities and project identities (2005: 347). ${ }^{23}$ In terms of the exhibition, the participants were generally resistant to the content, claiming they did not connect to the objects but understood the overriding message. They felt they had different experiences relative to the content.

The foreground for understanding the notion of difference, or that these identities are different, started in the beginning of the interviews. After discussing their impression of Passports the participants began by talking about their histories starting with their parents' tales of migration. The only participant who did not talk about this in the beginning was Anna, but she discussed it later on in her narrative.

Official statuses such as Permanent Residency and Citizenship aid in helping people of immigrant background to express their entitlement to feeling like a New Zealander (Anderson, 2008). We can link this to how Anna cited her connection to New Zealand as because she was born here and how this made it an embedded part of her identity.

Sarah also assertively stated her identity in terms of ethnicity and her parents' experiences as an integral part of her identity.

...At least I didn't have to go through a war in Cambodia and escape from Cambodia to another country where I didn't know the language. I'm quite privileged compared to what my parents went through and that's something I've always lived by. And something they've always told me when I was young was just how lucky I am that "you were

${ }^{23}$ A legitimizing identity "validates discourse", a_resistant identity "reacts to globalization by means of isolation" and a_project identity "reaches outward to connect with other people" (Saukko, 2005: 347). 
born in New Zealand." "You were born in New Zealand and you are very lucky," and my mum would always say "I've always wanted to go to school and so you should always try hard in school cause if I could go I definitely would," sort of thing. It's not like they were forcing me to live a life that they couldn't have but... I was always thinking about all the time and I always keep that in my head. It's made me want to do well in my life in New Zealand.

(Sarah)

The idea of migration within Sarah's story is similar to Alan's and Bernice's in the sense that both their heritages have involved war and that their parents reason for coming to New Zealand was not out of choice. In terms of the separation between her parents' and her own experience, there is disparity in terms of opportunity afforded but also a constant reminder of an experience and history that is dislocated from her current geography and situation. This feeling of displacement is something that contrasts with the inclusive feeling Te Papa aims to create through Passports. However, this sense of disjuncture between cultural geography and national situation is part of how the participants experience being Asian in New Zealand.

In this case, and in Alan's, there is the idea that this new place holds new opportunities but with a reminder that they are not from here. The values of Sarah and Alan's parents are inspired by their own countries which they only left behind because they were forced to. Here, Sarah and Alan are like gateways and translators between old beliefs back home and this new place.

Sarah also is similar to Alan because of her Chinese ethnicity but separates this from her attained inherent culture; "we're full Cambodian. I consider myself full Cambodian." Her history starts as Cambodian, but as her story progresses she revealed that this idea constantly changes relative to her age and stage.

Bernice is another participant whose parents migrated for political reasons, she at first talked quite abstractly about the idea of migration.

Migration always has the same problems. You don't have a structure when you get to the place you're going to. You have to build some kind of structure, you have to build your own community and in 
order to do that you have to stick to the traditions you knew before.

(Bernice)

After some prompting, she talked more specifically about her experiences of migrating and how migrating shaped her sense of self here in New Zealand.

\begin{abstract}
And I have a lot of my cultural background with the Indian community traditions and religion, but at the same time I have a lot of Pacific heritage as well. I see that as something that it essential to me. I know a lot of people wouldn't, it's only the last few years that I've embraced that feeling rather than early on. I wouldn't have necessarily called myself Indian cause that implies that I'm from India. I would have gone with Fijian Indian stating Fijian as first.
\end{abstract}

(Bernice)

Here, we can see that Bernice directly points out the disjuncture between sign and referent when she says that calling "myself Indian...implies that I'm from India". Furthermore, she says it is something she has only arrived at in the past few years, away from being in the Pacific. Bernice embodies the idea of a hybrid, cosmopolitan identity. ${ }^{24}$ She has experienced the situation of travel and uprooting one's identity and later grew to understand this as essential to her being. Despite these factors her ethnicity and geographic nationality are separate to each other. In terms of representation, she cannot be fixed to a set idea of ethnicity or nationality but is rather defined by cultural states and movements between her multiple identities and feelings of comfort in relation to the signifier used.

This idea of unfixing identity or having her identity challenged happened through the museum visit. The participants were resistant to the universalised New Zealand identity on display and felt different to the idea Passports aimed for. Feelings of being different varied among the participants but there was a sense they were unconscious about this difference until it was emphasised to them either by their family or peers. What exactly constitutes these differences has a direct relationship with being Asian but is also indiscriminate of specificity to Asianness, it is about

24 These terms were discussed in Chapter 1. 
the experience of difference within being Asian rather than being Asian itself.

Te Papa has used this idea of articulating difference as a strategy to unite differing ethnicities, claiming that we are all different and have contributed to the cultural fabric of New Zealand (Phillips, 1996). However, it is this very nature of difference, and the historical representation of Asians as different, which impinges on feeling as an accepted part of the norm. Te Papa's idyllic strategy is aspirational but does undermine the reality that some ethnicities are perceived as more different than others.

It is in these early stages of difference that I noticed how the process of multiple and changing identities first emerged and a different sense of self at home and "out in the world" emerged. Looking at Sarah's story we can see how her identity is constructed, deconstructed and reconstructed through reaction to how others see her and how she sees herself among this.
I was pure Khmer growing up. It wasn't till I started going to school that I realised that, we are a little bit different. You don't really notice it when you're younger but growing up when people or children are at an age who can judge you and you're around your best friend who is Kiwi with blonde hair, and then you notice okay, I'm different, and then you go over to their house and go over to play and that's when I started to notice things were quite different...It bothered me a bit that I was different when I was younger. (Sarah)

The idea of difference here is liminal in the sense that the difference is both to the idea of being full Cambodian and Kiwi. In this case, Sarah's identities rest in an intermediate space between being the same and being different. Her articulation of her identity could be read in Bhabha's terms of the third space (Bhabha in Papatergiadis, 1998), which is neither mainstream nor minority. It is through the experience of epiphany that she notices her difference and perhaps the museum could aim towards this feeling of epiphany in regards to national identity.

Similarly, Charles too had his sense of difference unnoticed until his classmates labelled him as different. 
It was a shock coming to New Zealand because I realised that many of my classmates didn't see me as a New Zealander. They saw me as someone who was Asian. This was quite a surprise to me as I never questioned my identity as a New Zealander even though I lived all my life overseas. We'd come back to New Zealand regularly for holidays, but I didn't speak English with a New Zealand accent so I was obviously different.

(Charles)

The idea of being Asian in Charles' statement was articulated in contrast to the idea of a New Zealander with the idea of they in contrast to the $I^{25}$ It is during these school years where we can see changing relationships of self and other beginning to be fostered. Notice how part of his relationship to New Zealand is based on his human relationships and how Charles sees himself as the same, while they saw him as different; Asian. His sense of inclusion was also based on the way they reacted to this referent and what this represented (different, Asian), despite the similarity in citizenship. His New Zealand identity is felt as an inherent part of his identity.

Each interviewee used a different way to differentiate themselves from normal during their formative school years.

In order to establish, me and my brother, we kind of lost a lot of our cultural things like our language and sense of dress in order to integrate but that's not to say we've completely lost the things. It's just that we diluted a lot of things in order to be accepted by our friends. The majority of them happen to be white or people not of colour, especially in Churton Park.

(Bernice)

In this case Bernice affiliates herself along with people of colour, whereas Sarah separates herself with the term Kiwi. Alan also refers to Kiwis or mainstream New Zealanders as Europeans, whereas Charles uses the term Pākehā and Anna uses white.

Criticisms of hybridity have focused on the idea of dilution as a negative idea compared to the articulation of cultural assimilation (Coombes, 1998: 486). In Bernice's case, it is not necessarily negative or positive but rather a necessity which aides her sense of acceptance and belonging in the new

\footnotetext{
25 Charles is half Pākehā and half Indonesian Chinese and spent formative years growing up in both Indonesia and New Zealand.
} 
place. Charles was the only participant who used a word from identity theory when he described himself: "I was a hybrid so that was hard to see."

Feelings of difference were not exclusive to relationships formed outside the household but also applied to generational differences and cultural differences at home in terms of negotiating the outside world in relation to the 'at home' world.

\begin{abstract}
...My parents were obviously Buddhist and Asian and stayed within their culture. But me and my sister grew up with TV and within the schooling system, so obviously we grew up very European and so our household it's a really interesting dynamic. I don't speak Vietnamese and they don't speak English...To communicate we don't really communicate as well as most parents and children do, but they're still stuck in their generation and me and my sister are definitely stuck in ours.

(Alan)
\end{abstract}

The difference between parents and children in this context is beyond generational and extends to cultural adaptations. The question this poses is what exactly constitutes ethnicity? In the context of New Zealand, the term Asian itself is a broad catch-all phrase swallowing different and distinct cultures (McKinnon,1996).

Here the difference becomes more complicated as it becomes less of a cultural aspect and moves toward the idea of being established in a country and the length of stay in that country.

The Fijian Indian community itself was really small and the only the community gatherings were weddings, prayer meetings and deaths... And a lot of people went to it not only to pray but also to connect to the community and because it was so small a lot of Fijian Indians didn't feel they could communicate or be accepted by the Indians who had been here generations before and there's definitely a break in there... $2^{\text {nd }}$ or $3^{\text {rd }} 4^{\text {th }}$ generations look down on you like the earlier generations.

(Bernice)

This relates to Ip \& Pang's studies of Asian New Zealanders and the lack of cohesion between Asian migrants who attempt to shake off their ethnicity in order to assimilate but are inevitably grouped with newer migrants (2005). Although the experience of being Asian is an overriding factor in identity-making a reversion back to essentialist ideas surrounding 
ethnicity and race is reductive and disregards the idea of selfdetermination beyond these categories.

Similarly Anna's story shared these sentiments.

My Asian friends are not like the ones... they're all born here like me they're not just here for a short time like those exchange students or not like the ones who can't really speak English, not like those. They are more like me, their parents have come from a different country and they've settled here and they've had children and stayed with their families. Cause then they've been brought up in New Zealand but they've still got that Asian influence.

(Anna)

Here we can see an experience of identity going beyond the idea of ethnicity. Being 'like me' for Anna means being both Asian and a New Zealander. We can see the formation of distinctions of self and other that speak more closely to relative cultural situations rather than an overarching ethnic bond. However, what also emerges is changing relationships of self and other. For example, Anna is the same as Asians who were born here but changes her stance in relation to 'those who can't really speak English.' Although there is the idea of adaptability in culturally relating, there is also a sense of disparity between experiences. In comparison to newer migrants Anna assumes the majority position. However in relation to the majority, a minority or different position is taken. This is problematic in terms of identifying as being the same and different. Through Passports the idea of being the 'same but different' is the essence to being a New Zealander; we have all come here and, despite our cultural differences, are still New Zealanders.

These narratives provide an insight into the way identity is articulated. This poses questions for museum representation of the most effective way to envelope feelings of national pride and inclusion without disrespecting the experiences that are specific because of cultural constructions. The idea of difference is described as a feeling of epiphany, not necessarily attached to certain materials or values but a visceral response to the realisation of difference which, to an extent, is un-representable. 
It was apparent that the idea of 'difference' was something quite hard to explain but always in mind, especially in connection to talking about what it means to be a New Zealander and what it means to be an Asian person in New Zealand. All the participants identified with the term 'New Zealander' or its concepts through different terms such as Kiwi, or characteristics they believed to be symptomatic of being a New Zealander. Through the different stories it became clear identity was arrived at from differing points and through differing experiences. Despite the specificities of each story, and idiosyncrasies of each cultural subset, the findings and analysis still prove there is a communal narrative. This is based on similar experiences of holding multiple identities and ways to navigate the conflicting cultural terrain in this post-colonial time. Te Papa should retain this sense of inclusion of engendering national pride. Despite this sense of comfort with switching between New Zealand and Asian identities we also see that there are differing cultural identities adopted at home and outside of the household.

\section{Public versus private identities}

In some of the case studies there were contrasting cultural values in terms of parents' beliefs versus the new ideas and cultural practices adopted here in New Zealand. Values and experience from the migrant population adapt to the local values and experiences by way of amalgamation. Although this new hybrid and cosmopolitan culture is autonomous from both New Zealand and Asian specificities, they are still located within these spheres of thinking.

In Anna's narrative, she displayed a lot of freedom in terms of the lifestyle she chooses and how it is very much of her own making and decisions. However when she discusses her 'at home' life she says "I still consider my culture to be Kiwi maybe just the way I act and the way I dress is still New Zealand. But just at home it's different you can't change that, I guess you can't change your parents' culture." For Anna the 'at home' culture is the 
stable and fixed tradition of doing things, whereas it is the outer world that is changeable and self-determining.

Sarah cites the conflict between being an insider and outsider from the differing opinions of what her parents felt her traditions should be and the friendships she wanted to be part of.

...I went through a feminist phase in college and high school where we learnt about feminism in history and suffragettes. So I got into feminism quite a bit. And I always told my mum you should really treat me the same as Bunna and Michael because in this country everyone is treated the same and them my mum would always tell me, "it doesn't matter because you're not Kiwi you're Cambodian." "that's how we raise you. You're living in New Zealand but you're raised as a Cambodian." Growing up as a teenager a lot of the time I just thought it was really silly and I always considered myself Kiwi. Because I was raised here and I was raised around Kiwi people as all my peers.

(Sarah)

She also goes further in her first narrative, talking about acts of concealing her Kiwi identity from her parents in order to "fit in" with New Zealanders whom she felt a desire to be the same as. ${ }^{26}$ When asked about what it means for her to be Asian she talked about this identity in a way that is slightly separate to whom she is now.

I think to me it's the just way I was brought up. I think it is my parents. I look Asian but at the same time you know I think the most Asian thing about me was the way I was brought up. We were brought up so differently that's how I differentiate myself from a non-Asian person.

(Sarah)

Although the idea of difference is avoided due to the desire to be the same, it is inextricably linked to the process of identity making, how a sense of self is defined, and what makes this experience similar and collective among the other participants. After this answer was given I asked Sarah "what, to you, is being a New Zealander?"

Being a New Zealander is, I guess, growing up in New Zealand away, outside of my household. I guess being at home is being Asian and

\footnotetext{
26 This research considers the term "fit in" to mean "assimilate", "integrate" or "be the same" as suggested by the way the participants used this term.
} 
being outside of home is being Kiwi. It's like being out in the environment. You're being brought up around other New Zealanders.

(Sarah)

From this it can be concluded that there are two types of upbringing. One which is 'at home' under the parents' gaze. The other is 'in the world' where the interviewees have to fit into New Zealand despite conflicting values. The 'at home' culture and 'in the world' culture can be quite separate cultural environments, with different identities activated. Despite the idea of being away or identity as an outsource of the immediate environment; articulated and realised somewhat outside of home and beyond the understanding of peers in the outside world, there is still a sense of locality within this process of identity making, that while it resides outside the home, there remains a feeling of it being constituted in this time and place.

Although it is natural to assume different public and private identities, is this presumption of different cultural identities something common? Perhaps what should be understood through this analysis, so far, is the idea of spaces in which to feel culturally accommodated. Sarah's Kiwi identity was not as accommodated at home when she was a teenager, so she emphasised this in her outside world. On the reverse, her Asian cultural identity was not accommodated by her peers. This impacted on her sense of belonging and the way she understood her situation in New Zealand.

Museums are storehouses of culture and places of affirmation of cultural identity (Mason, 2005). They are institutions which aim to culturally accommodate disparate social groups (Pieterse, 2005). In terms of Asian New Zealanders and their representation, the museum is a place that has potential to accommodate both public and private identities.

Coombes (1998) cautions against viewing the amalgamation of two different cultures as meaning they are compatible. It is important to show the complexity of these negotiations; identities shift, adapt, relate, and connect, not merely because it is an option. The participants felt distanced not only from the Asian material on display in Passports but also from the idea of a New Zealander that exhibition suggested. 
In differing situations the participants expressed connections to being Asian and being a New Zealander. By virtue of their experiences they also felt some distance to both these terms and did not adopt them whole heartedly in either an inherent way or through relating culturally. What was prominent was that stories surrounding upbringing and their parents' tales of migration and settling affected their sense of belonging-growing up like this was different to the other children. In some aspects, these people also acted as aids to integration or what Sarah coined "the transition phase" between being an outsider to their parents' generation to an insider through education of the New Zealand culture.

\section{The difference between being and seeing Asian}

Although identity is a culturally relative situation built upon cultural resources, it is safe to say that this undermines the idea that identity is instinctual and about emotionally relating.

Looking at Sarah's story it became apparent she had always understood her heritage and is unwavering in her connection to her parents' ethnicity and history as Cambodian refugees who arrived in New Zealand. She talked about how, when she was growing up, part of her feeling of exclusion resulted from assumed cultural references which were beyond her parents' history. She cites episodes growing up where these assumed universal cultural references impeded on her sense of belonging.

I could never go home and ask my mum "oh my social studies teacher told me to ask you about a TV show in the 80s that everyone watched like what was that character from that show?" I could never go home and ask that because they didn't grow up here, it's just something that's always, always bothered me when I was younger... It's something that makes me different from everyone else.

Sarah speaks of a desire to go beyond assumed cultural references. As discussed, the idea of being Asian in New Zealand has evolved from being an ethnic, inherent quality to being a subjective, cultural category dependent on social and political factors of the New Zealand climate. The interviews reflected this with an affinity of similar experiences with other 
Asian people as opposed to a unifying umbrella idea of inherent ethnic codes. This is problematic in terms of the current method of inclusion for Passports because the premise for identification in the exhibit is through ethnicity and nationality.

It was these formative years where the idea of prescribed identities were resisted and rejected by the participants.

They never really enforced their culture too much on to us as kids... I guess that's part of the communication barrier again, our parents couldn't really speak to us and we couldn't really ask them questions and we just did it 'cause that's what was done. So in terms of that I don't really have an understanding of my own heritage which is kind of a shame...I guess it's always been blurred in the sense that... My position in society is that largely all my friends are European and that's how it was. In primary school there weren't too many Chinese people. At high school... In Palmerston North it was really European so I never really associated myself with Asians... So I don't know too much about the culture or the mannerisms and behavioural things, but I grew up very European, very assimilated despite the fact that my parents were the generation that weren't assimilated and so obviously when you're growing up in my era in my age kids were quite mean...

Upon reflection, being Asian is something Alan never consciously connected to. If identity-making is a process then there must be arrival and departure points along its course. The idea of being blurred encapsulates the rupture between having something which is supposed to be an inherent part of you and growing up in an environment which is unaccommodating of cultural difference. Although the relationship between Alan and his parents seems unorthodox there are different terms of cultural engagement for those who are in between two spaces.

In the second interview when I asked him to expand on his sense of being blurred he said

Well, I guess my family didn't really hang out with many Chinese people. So, the contact that I got in terms of face to face and human contact was largely European and it's just what I got accustomed to... I just feel as if I didn't notice it really at all. I can't think of a scenario where it's come up and I've felt on the outside completely.

(Alan) 
Despite his external environment being European, Alan later talks about how it is different at home alluding to the shifting, hybrid ways we hold public and private identities.

With Bernice it was a contrast again. Her identities shift dependent on where she is, even in a New Zealand context.

I remember when we moved from Churton Park to Newtown we had such a shock that there were people of colour and ethnicities. Wow, what happened! It was almost like we had to rethink who we are in order to fit in again.

(Bernice)

Bernice's identities are relational and shift even within a local context. She shows how it is not always about going back and forward or rejection or denial but rather about adaptation.

What I noticed was that school environments, or environments in which other people emphasised 'being different', is where difference was most felt. In the context of museums, the idea of difference is always celebrated and emphasised. However this celebratory sentiment is not reflective of the way difference is used as a weapon for division and how an emphasis on difference undermines the unity between people.

Bernice also spoke about this ambiguous position between being and not being a New Zealander.

I don't know if I went to another place if people would pick up I'm actually from Wellington... You know that question "where are you from?" And whenever you say Wellington or New Zealand you kind of feel like you're lying a little bit. Even though you know it's completely true you've lived half your years here... It's like you should put a disclaimer in there, you were born somewhere else but you're definitely a New Zealander. You have to state it, I know these things, I'm not a visitor to this place and its quite odd in that respect.

It seems that there is this desire to 'prove' nationality despite the representational misunderstanding that ethnicity poses. This is also an idea posed by Ip \& Pang about ethnic minorities having to prove their national identities (2005). Even though inherently people feel connections and 
conviction in who they, identity is called into question if the projected representation does not match the person which, as we can see through Bernice's experience, has a reflexive impact on the way someone understands their own representation.

When asked about the common migrant experience and if there would be an overarching thread to the idea, Charles theorised about the status of Asian people and their subsequent integration into the idea of being a New Zealander.
I think a common thread would be their identity as New Zealanders; how they see themselves as New Zealanders but not be seen by the majority of New Zealanders as fellow New Zealanders. I think this is a huge issue. I think the fact that there are many Asian New Zealanders and many other ethnicities who have come here, been here a long time, have New Zealand citizenship or are permanent residents consider themselves New Zealanders but not be have their national loyalties questioned because they look different. I think New Zealanders haven't got their heads around the fact that there is an Asian component in New Zealand identity. I think that New Zealanders think that a New Zealander is a Päkehā person, a Màori person and there is increasing acceptance that there might be a person of Pacific Island ancestry but when are they going to come around to thinking well, also it could be a person of Asian ancestry?
(Charles)

The frustration displayed here shows a tension between having to earn the privilege of a New Zealand identity and having it understood as an inherent part of who can share in that identity. Charles also inevitably ties this back to the idea of the physical representation of being Asian and what this means as a signifier.

Despite Alan's earlier sentiments about sameness and difference and the desire to be understood, we see through Sarah's story that experiences about affinity and allegiance are formed through this desire for acceptance within a collective group.

... I was picked on quite a bit at intermediate and it bothered me because I knew I was slightly different... I went to Raroa and after school everyone would go to Johnsonville Mall just to hang out there and I would have to go straight home because my mum would just 
wonder what is the point of going to the mall and hanging out. "You shouldn't do that because we don't do that, you come home straight after school," kind of thing. I mean I wanted to hang out with them cause I wanted to fit in but then.... I met Ida. She is a friend that I met when I was eleven and she is still one of my closest friends now because she was one of the people that I felt really, really close to because she's Malaysian and her parents have brought her up almost exactly the same as my parents... And just-I'm not trying to be racist or anything - but you kind of automatically are attracted to people who look like you and you feel more comfortable and are able to express yourself.

(Sarah)

This poses an interesting argument for the nature of experience for Asian New Zealanders. It is not necessarily one derived from the specificities of ethnicity or culture but rather through a cultural situation created by this specific difference of being Asian in a New Zealand context. Allegiance is created by a sign, people who look like you, and its correspondence to the signifier, her parents have brought her up almost exactly the same as my parents demonstrating the nature of representation.

Through negotiating both identities Bernice belongs to both New Zealand and Fiji but this identity was not arrived at without the fraught process of 'diluting' and 'doing what you need to fit in'.

The only way to make things easier is to try and integrate... It's only now later in my life that I'm clutching to my heritage and not necessarily Indian heritage but heritage from the Pacific... I know when I was 16 I went back to Fiji and I hated it... It was too hot, there were no books around. All the things that you grow up accustomed to weren't available anymore and you think how could I have lived without this, and I guess if you don't know then you don't really miss it... And I wonder if it's because it's such an idealised feeling of belonging. I wouldn't say that now I completely belong there like I belong in New Zealand as well, but at the same time I know that my upbringing is way different to most of my friends. (Bernice)

The idea of an idealised feeling of belonging speaks beyond a desire to be recognised as the same but also reveals a desire for a genuine connection to place, culturally and emotionally. 
Alan is more overt about the idea of being liminal or hybrid, about existing outside of both spaces and simultaneously feeling attached to and detached from both.

When I say blurred I say I don't completely fit into the European side of things or the Asian side of things. I identify with both but feel as if I'm on the outside of both. I guess it's all about making your own little niche as opposed to trying to fit in, so that's the direction I've taken. When I was younger I thought about it a lot and didn't like not being part of a group, but as I've grown up, I don't know. I've just become confident enough in myself to be myself-to be a bit of both. In terms of culture... it's more European but it's not as if I'm going to shun my Asian side because I live a European lifestyle. I don't feel as if I'm ashamed of being Asian at all and I don't feel as if I should hide the European side of me from the Asian people... I will just let them know this is how I do it. This is how we do it in New Zealand.

(Alan)

Debates centred on hybridity suggest a new culture emerges from the friction of experience between mainstream and minority, migration and travel (Araeen, 2002; Bhabha in Papastergiadis, 1998; Coombes, 1998). However, to a certain degree these arguments suggest a limitation. It feels ineffective to have a specifically unspecific 'new' culture floating like an unknown entity between old and new. Despite the newness of a culture which emerges from two spaces, they are also firmly rooted in historical articulations of place and representation; that are neither exclusively Asian nor New Zealand experiences.

Museums are spaces to feel a sense of national belonging, within Te Papa's mandate it aims to accommodate the diversity of New Zealand and unite this diversity (Te Papa 2009-12). Museums need to ensure cultural safety by carefully choosing how to represent this diversity. By placing something material to stand as a metaphor for a social group, museums fall into the idea of categorisation and are at potential risk of stereotyping, despite good intentions.

In reacting to the stereotype of Asian people some of the participants had differing perceptions of what signifiers were attached to this label. They affirmed stereotypes by giving their ideas on what they thought constituted 
Asian culture but also denied this by citing their own experiences as separate to what is encompassed within this category.

For example Alan talks about his cousins and how they are very Asian.

My parents have been very flexible. I think it's more of New Zealand side of things and the fact that if they grew up with their family around them in an Asian culture I think they would have been quite strict.

Being Asian and strictness are associated together whereas New

Zealandness and freedom and flexibility are cited as influences on culture.

Similarly Sarah associated with the stereotype of Asian studiousness within her household but also talked about how she went against it.

I got my first job when I was fifteen but that was against mum and dads wishes. Dad probably wouldn't have mind but mum was always about study. "You don't need to work because your dad and I are the hard workers we're the ones that are providing for you..." Sort of thing and I guess... at first I didn't see the point of it.

(Sarah)

In the context of this passage Sarah theorises that the strictness and focus on education was to take advantage of opportunities her parents did not have. She talked about how she did not see the point of it but now reflectively understands the reasons behind it. ${ }^{27}$ She also talked about how this was different to New Zealand culture because of different cultural world views and experiences which are not compatible with our parents' and this creates distance.

That stuff... it's so normal to Kiwi culture. I think Kiwi parents accept it 'cause that's just what they do. Whereas our parents are just like "that

27 ...She'd tucking me in and telling me stories about how she'd be walking through the jungle with my dad with her brothers and sisters and seeing dead bodies hanging through trees and stuff. It's probably not something you should tell a ten-year-old but she used to tell me every single night and I'd listen... It's not until you grow up its when you realise. I think that's why I never have tried to directly hurt my parents by disobeying them in any way. As much as I wanted to fit in with my peers I would never do anything to disobey them... But I did anyway, I did rebel a bit.

(Sarah) 
just never happens," "no you don't do that," "just because you're living here doesn't mean you can do it, 'cause you're Cambodian”. (Sarah)

\section{Summary: perspective}

From the material discussed in this chapter it feels as if the experience of being Asian is earned through experiences shaped by being in New Zealand as opposed to being inherent. Demos talks about the idea of perspective and that negotiating multiple ideologies and articulations of self is like a vantage point for seeing.

This 'double perspective' (in Said's words), a 'double frame' (in Homi $\mathrm{K}$. Bhabha's) results from the bi-cultural knowledge it produces, generating in its positive expression a sensitivity towards difference (that of cultures, places and communities), and a newfound appreciation of the cultural character of one's origins when looking back from exile's awry vantage (Demos, 2009: 73).

From their experiences, the participants have encountered an unsettling feeling of displacement, both from the land of their parents' heritage and from their imposed representation in their own homeland. From this chapter I have analysed the experiences and reflections which create that sense of vantage and how this impacts on not only belonging but ways that we create ourselves in relation to how we think we should be understood. The cold comfort of "exile's awry vantage" is this unique empathy and perspective.

This chapter looked at the formative years of identity making where their ideas about their own identities were fostered, challenged, deconstructed and reconstructed. What was revealed was that it was everyday, commonplace occurrences that constituted the idea of difference. The participants used these experiences to evaluate how they stood in the schema of New Zealand identities. The next chapter will build on this by looking at the ways multiple identities are negotiated and how the participants easily slip in and out of different identities as a method of relating and belonging. 
In terms of the museum and the implications of this perspective: firstly, it is this perspective from which we view the material within Passports. It is not through an embodied experience but rather a distanced view. The encounter with 'ourselves' through exhibition becomes a comparative act, we see ourselves represented and look at how much we can see our identities reflected. To better understand occupying this 'third-space' between mainstream and minority is not a material undertaking. It is implied, intellectual and considered. Furthermore, from the biographies so far, we understand that a sense of "difference" precedes the visit to the museum. The participants responded to the exhibition not necessarily through empathy but rather considered how they see their own lives and histories here in New Zealand. It is within this act of creating and reacting to representation that they construct who they are.

From their stories it became apparent the participants were not necessarily conscious of 'being Asian' or conscious of this identity until confronted by it, usually from the realisation of difference between themselves and other New Zealanders. This idea aligns with Hall's theory that identity in itself is a reflexive process, and in order for it be 'activated' conversation with an external perception is required (Hall 1996). Resources from the museum were used and this related to "how that might bear on how we represent ourselves" (Hall, 1996: 4) as discussed at the beginnning of this chapter.

For this conversation with representation to be enabled, it is important for cultural forums such as museums to provide stimulus for inclusion and discussion.

The next sections will discuss what exactly constitutes the experience of being an Asian New Zealander and the opportunities for representation the national museum can undertake. It is in the next chapter where the idea of multiple identities and negotiating and navigating the multiple perspectives of the participants will be discussed. 


\section{Chapter 5: Navigating}

\section{Introduction}

Communities are to be distinguished, not by their falsity/genuineness, but by the style in which they are imagined. Javanese villagers have always been known that they are connected to people they have never seen but these ties were once imagined particularistically as indefinitely stretchable nets of kinships and clientship (Anderson, 1991: 15).

...there are no longer cultural roots to sustain forms, no exact cultural base to serve as a benchmark for variations, no nucleus, no boundaries for artistic language. Today's artists, in order to arrive at precise points, take their starting-point global culture and no longer the reverse. The line is more important than the points along its length (Bourriaud, 2009: 14).

If we take Bourriaud's line and apply it beyond the realm of creative practice we begin to comprehend that understanding ourselves-in relation to each other and the perspective gained from this vantage pointis also a creative act.

This chapter will show how the participants have arrived at a point of their identity building where the terms Asian and New Zealander do not need to exclusively co-exist. What is seen is the way these multiple, mediated identities are negotiated and how they strategically find strength in this position to navigate their sense of belonging and make connections to place. This position is flexible and malleable depending on situation and context. Despite the diversity of the participants it was found that the unifier of this group was the process and experience of negotiating this identity, formed a kinship based on the inadequacy of understanding that this ethnic group faces in New Zealand. It is an experience accumulative of being Asian and New Zealanders, uniquely resting between both spaces, tied to and unfixed to both.

Although our national myth of migration focuses on the journey and landing (Phillips 1996), the process of travel and arrival points are not necessarily geographic, but emotionally responsive and can be read as 
arrival and departure points of identity making. This terrain also speaks to the way communities are created; they are not at all objective, but hold an affinity between members which speaks beyond the clinical reserve of categorisation (Anderson, 1991). For Asian New Zealanders this imagined community emerges out of a tension between this cultural construction and something intuitive gained from a collective experience. This is something that became increasingly evident throughout the interviews. The perspective gained by the participants from their earned Asian identity allowed them to understand each other beyond the premise of ethnicity while being simultaneously bound by it.

An imagined community could also be created out of interest or mutual understanding-social groups or "neotribes" which cultural nomads can adopt or abandon at will (Bennett, 1999). Bennett connects neotribalism to consumer culture. However, this idea is not as easily applied to the conceptual or embodied terrain of ethnicity. One can choose to be a museologist but can never deny being Asian. Ideologically one could, but physically never. This is part of negotiating these identities. Although theories of race are deemed crass and outmoded, to a certain degree they still determine the way we understand how we see each other and ourselves. Despite how unharmonious or in sync this lens may be with how we determine ourselves, the realisation that we are to a certain degree visual signifiers is undeniable. This idea aligns with the participants' experiences where it is not only an articulated, cultural feeling but also an embodied one.

If we do take Bourriaud's idea of the journey, then we understand that for the hybrid Asian New Zealanders, identity is not solely about selfdetermination. It is also about navigating those prescribed identities, modifying feelings with histories and ideals with realities. This chapter will analyse how the participants navigate their way through the terrain of identity making and juggling who they are with and how they want to be seen and understood. 
Both Anderson and Bourriaud provide positional statements about how identities are made and understood, as both relational and reactive. Although experiences and background history can give us an understanding of how identities are made and communities created, this cannot necessarily explain the intuitive bond or affinity created by this experience. What emerged in the interviews was the idea of a feeling of affinity which was unexplainable in words. The participants attempted to theorise this themselves through what they understood about being Asian and being a New Zealander.

The previous chapters used the idea of encounters and experiences as signposts to how the participants understood themselves in regards to feeling like a New Zealander. This chapter aims to cover more conceptual ideas that were elicited from the participants' responses. I will discuss the ideas that emerged through the interviews and show the limitations if we read the words of the participants only in terms of identity theory. The ideas discussed will attempt to show a direction of representation that speaks beyond ethnicity. For structural purposes this section is also divided into themes but is comprised of excerpts taken from the latter part of the interviews to show the progressive narrative that emerged.

\section{From ethnic to cultural category: affinity as the unifier}

From the narratives given, we see how the boundaries between ethnic and cultural categories are blurred and that ethnicity holds no currency without the traditions and experiences that a culture creates. The unifier of this group is shared experience rather than ethnicity.

Te Papa's bicultural structure is reflected in Mana Whenua and Passports. Mana Whenua is the space for the Tangata Whenua of New Zealand and Passports attempts to reflect all the other migrants that have come and settled in New Zealand. The problem with this structure is the minority immigrants get swallowed into the majority story; these stories are quite separate from each other. 
It is more appropriate to investigate the role of affinity within these stories.

This would put the emphasis on unity as opposed to 'difference'. ${ }^{28}$ This affinity would show that despite 'us and them' relationships-changing articulations of self and other-there is a fundamental affinity within the Asian experience in New Zealand. This experience is not necessarily consistent but rather something that connects one Asian to another, something unexplainable but emotive and experiential.

Sarah talks about her connections with the other Asians-friends she made at university. In the passage below she has changing relationships of being 'other' to them and also being the same as them.

In my first year I made friends with tonnes of International students...Straight away I didn't really get along with them they just kind of hung out by themselves and I was like 'oh my God so many Asians in that corner'. Later on they revealed to me that they didn't even like me. Their first impression... They just thought I was stuck up and apparently my demeanour I'd come across as really grumpy and stuff, which is fine, but I think it's because they know, you can just tell that we're different. Like we're both from South East Asia but because they're International students they can just tell. Maybe just by body language, who you hang out with, what you wear and things like that. So to them I was really, really Kiwi. But we look the same, you know? For some reason, I felt really close to them. Like I belonged with them as well. Like I felt like I fit in really well with them even though they weren't Kiwi but at the same time I feel like I fit in with my Kiwi peers as well.

Perhaps it is like Bernice's idea of identity when "It's a lot of common kind of experiences that has happened when you become a minority as well."

Being a minority is a learned experience and not inherent to a particular ethnicity.

Within the following passage Sarah is part of the majority. Her connection and experiences of minority allow her to connect and understand not only

28 The strategy that Te Papa has used, and is commonly used by museums, is the idea of celebrating difference. Although this idea does have its merits is also undermines the desire for similarities amongst migrant groups. The danger with celebrating difference is that these celebrations are often reductive and do not reveal the complexities of being different. 
at a signifying level (we are Asian therefore we are the same) but also at an experiential one.

I don't think I had much in common with them because I think if they weren't Asian I wouldn't have been friends with them. I know that's quite weird to say but I was just weirdly drawn to them. I don't know if it's because they look like me but at the same time I know that their upbringing would be similar to me. They were brought up the same but at the same time different because they were international students. So it's different in that sense but I think just the whole Pākehā Kiwi thinking and Asian thinking it's just slightly different. I think subconsciously you just get drawn to it. But yeah I think that's all we had in common with each other. I think if they weren't Asian... Some of them weren't even my type, I just hung out with them anyway.

(Sarah)

Although Sarah is of a different ethnicity to her international student Thai friends, they formed an affinity through the experience of being a minority. They are fundamentally the same as her.

Bernice too identifies this need to connect on an experiential level, "It feels like you belong somewhere and you feel understood within that community because they're almost like a huge group of minorities that are sticking together." This idea of shared identity beyond the confines of ethnicity is something worthy of further investigation. What Bernice reveals is how cultures are created as a result of the conditions of the host environment. These ideas are explored by Anico (2009) where heritage is understood as a cultural construction. The display of identity can either be seen as forums for the debate of what constitutes particular identities or "identity bunkers" which restrict and essentialise. Te Papa can act as this forum for the debate of what constitutes both national and ethnic identity; it is also a public site where this sentiment of national unity and understanding is supposed to be fostered. Te Papa aspires to be a forum for the nation (Fitzgerald, 2009: 198).

The above excerpts show how a feeling of affinity can emerge from an empathetic experience or through an experience that has been imposed. The next section looks at the nature of this imposition on identity and of the idea of choice within identity making. 


\section{Choice}

So far, the way identities have been discussed has been in a relational context and has emphasised the subjectivity of the identification process by contesting connections to both a New Zealand identity and Asian identity. However, the process of identification and communal experience is not always about choice. Being Asian is a sign which carries certain connotations and denotations which are not necessarily constructed by the person who carries them but are still tagged to the ideas they encompass (Hall, 1997; Lidchi, 1997).

This idea about choice in identity politics is fundamental to consider because of the way it shows how we cannot completely control our representations. This means there is always an aspect of identity making that is outside of our power. This is what keeps certain groups from being able to be understood and read in certain ways (Anderson, 1991). During the narratives participants revealed having to negotiate choice in determining aspects of their identities that are imposed upon them.

Bernice talked at length about how being in New Zealand allowed her to identify with her Pacific heritage. She considered that this may not have been the case if she had stayed in Fiji where she would have categorically been considered Indian rather than Fijian. On asking her about identifying and whether or not this was a matter of choice she replied

\section{I don't think it's solely about choice. You can't change the colour of your skin or like the way you speak because you'll always be identified at some point. But you can choose to accept and change some parts about yourself that might have not have necessarily been where your culture's values are. \\ (Bernice)}

She also discussed how there are more choices in New Zealand but how this idea also contradicts certain values she had been brought up with. This was the case for Anna, Alan and Sarah too, where the choice to be a New Zealander was going against parental or cultural belief systems and traditions. 
One of my huge memories in the last 10 years is me signing a contract to have a room at a City Council flat, and that was just me signing a contract and I remember doing that and just thinking that's it. That just breaks everything from my family... I remember signing that contract and thinking that I was breaking that slightly, it wasn't like I was the only person in the world doing it, but it felt like a really big moment for me and I remember thinking I can't go back from this point.

(Bernice)

A rite of passage in New Zealand culture-leaving home-was described by Bernice as a significant event and understood as an emancipation from cultural expectations. Whether conscious or not, there are certain acts which provoke a sense of 'betrayal' to one's parents' culture or acts of actively going against their culture in order to determine one's own culture as a result of having access to two worlds.

Sarah too, actively went against what her perceptions of her parents' culture were in order to 'fit in' and as an act of self-determination. This was her response to the question, "what to you is fitting in?"

Just not being seen as someone who was brought up differently... Those sorts of things like concealing it and concealing being Kiwi from them was because I thought they would get hurt by it, "you're Cambodian you don't do the same things as those people." Whereas at the same time as being what my parents wanted me to be. It was quite conflicting.

(Sarah)

These ideas about conflicting identities and going against what is expected of you hinder feelings of belonging within both worlds. The idea of choice in creating identity is liberating but also impedes feelings of acceptance.

Yeah I guess it's creating your own set of idiosyncrasies and I guess it's being more aware of yourself so you're not just becoming this automatic cliché, you're creating your own identity. (Alan)

However within this lack of choice Alan talks about creating his own niche which has allusions to creating your own culture within the cultural peripheries. Araeen's theory of hybridity depends on this space in order to have access to both mainstream and minority worlds (2002). Perhaps this idea of creating cultures which connect and do not connect to both worlds is a survival mechanism for identity. Alan is also conscious of clichés and is 
reacting to the idea of the stereotype. Signifiers in the public arena need to go beyond expectations in terms of what is conventionally understood as being Asian. For example if we take an iconic New Zealand object like a rugby jersey and attribute it belonging to an Asian New Zealander we can see how museums can manipulate conventional hegemonic tales and use subversive tactics that challenge public perception.

Integration, which implies a natural merging of both worlds under the spearhead of the majority, in this case New Zealand, can also be somewhat problematic because of ideas about 'betrayal.' When asking Bernice about integration she replied "it's definitely not a natural thing at all, there's nothing natural about it." In terms of Bernice's response to integration, I can recognise that the idea of a New Zealand identity also has signs and signifiers loaded with meaning and expectations. ${ }^{29}$ The idea that integration is unnatural also affects feelings of belonging. However, these sentiments differ from Alan who was born in New Zealand and grew up very assimilated.

Another aspect which hindered participants' sense of belonging was experiences of discrimination. All the participants alluded to this experience. It is this feeling which is specific to being an Asian New Zealander and united their experiences. There is a sense of unearned injustice in reference to discrimination. It is also this experience which serves as a cohesive empathy point for Charles, who is of mixed ethnicity.

I do think that people of mixed ethnicity that were born here probably could quite easily escape feeling discriminated against. I do think that. Especially if they've got a European name and might not look Asian...

But then again you've got to also ask those kids about their identity and whether they feel Asian, I think many would probably struggle with their ethnic Identity.

\footnotetext{
${ }^{29}$ I really don't want to feel I'm taking things out of tokenism and it's like a real need to understand. I think at the same time I'm not really into rugby and I don't really care about doing Kiwi things but just if I had to tell someone overseas where I'm from and what nationality I am I will always tell them I'm a New Zealander rather than a Fijian Indian. It's quite difficult to say because at the same time I'm not only a New Zealander.
} 
For Charles, this empathy with experiences of discrimination targeted at Asian people is fundamental to identifying as Asian.

Anna had an interesting way of dealing with racism by separating herself from it because of her connection to being a New Zealander. ${ }^{30}$ "I think in a way it doesn't affect me 'cause I don't feel like one of them... I was brought up here so I'm a New Zealander."

These experiences are a reminder that although an idyllic vision of hybridity envisages people being able to pick and choose between different identities there is also the experience of being unable to escape categorisation or the negative experiences which come with it. Within Passports there are many choices the visitor has in terms of both exhibition route and what material to read. However, in terms of having an identity imposed on you or navigating the identities you subscribe to, it is not a matter of choice but negotiation.

\section{Beyond ethnicity}

As discussed throughout my analysis, ethnicity is an integral part of who the participants are but not exhaustive of who they are. Their own understandings of Asianness are not necessarily consistent with each other. The participants made choices as to which ideas to adopt and/or resist in regards to the Asian material on display through Passports. The participants' ideas about Asian ethnicity contradicted the notion that this is something stable and fixed. The experiences of the participants are unique and individual-and should be respected as such-but also reach towards the idea of affinity which can only emerge through this experience of feeling ambiguous about these identity prescriptions.

The migration story is still important but perhaps does not hold the same significance the older generations of migrants placed upon it. The focus

\footnotetext{
30 Anna was the only participant who did not talk about experiences of racism in a personal tone.
} 
now seems to be on being and living in New Zealand and the experiences that form the understanding of the here and now.

A recurring theme throughout the interviews was the idea of associating New Zealand with the freedom to be whoever they chose (in terms of identity building). The understanding that New Zealand has fewer social restrictions than their countries of heritage has allowed them to explore ideas about liberation and choice. This was reflected in the way participants slipped in and out of different identities. Perhaps because of the socio-political situation of New Zealand participants found it is much easier to be able to not be confined by markers of ethnicity.

A common remark about New Zealanders was the 'laid back' attitude which can be read as a stereotype but there were also ideas about New Zealand that were not necessarily definable.

I love being a New Zealander but I wouldn't be able to necessarily define what being a New Zealander means...But for me it offers freedom from where I could have been....As a New Zealander I don't know if there's like I mean there's no set common identity of a New Zealander but for me it's a lot of freedom.

(Bernice)

Perhaps this can be read as a reflection of the participants' understanding of themselves as New Zealanders; how their ambiguous position is reflected in the way they understand themselves to be both New Zealanders and non-New Zealanders. Being in New Zealand also gives Bernice the freedom to explore her Pacific Island heritage, a connection she talks at length and affectionately about. Because of her situation in New Zealand, her sense attachment to the Pacific increases in relation to being Fijian Indian.

I don't think I'll just be one [culture]... I don't know if I stayed in that one culture [Fiji] I would be able to call myself Fijian Indian. At the same time I wouldn't be Fijian there would always be a barrier. And I don't know even if I was India I would be Indian. I'm not Indian, I'm Fijian Indian. There's always like this thing there to stop you saying you're just this one person, one culture.

(Bernice)

Alan too, discusses the way New Zealand means freedom 
I think it's all about being able to do and say and being able to identify yourself with a few groups not just one. So you're free to be who you want to be so in terms of being Kiwi it's about freedom to be expressive and freedom to move and freedom to grow really. I think we're a really open society because of it.

(Alan)

Despite experiences of racism the participants' feeling of national pride and affiliation was still intact.

It is interesting to note that when talking about being a New Zealander Alan includes himself in the term with the use of "we're". The idea of being a New Zealander and being more than one identity acknowledges his own articulation of his identity.

The idea of "calling New Zealand home"' is theorised by Sarah as no longer exclusive to those who have parental heritage here or even to those who are born here. The concept of New Zealand as a diverse, inclusive society is understood universally among the participants and, although birthright and citizenship were cited as important for feelings of belonging, it seems these are no longer exclusive criteria in order to connect to a collective feeling of national belonging. The idea about "being" and "becoming" is emphasised by Sarah and how accessible it is to become Kiwi.

In Sarah's narrative I was included in the term we, both as New Zealand born Asians and as Asian people with experiences of exclusion. When asked about being Asian there were differing responses. Part of the problem is what exactly this term means and how people relate to it. It was generally understood no one could speak on behalf of the entire Asian experience because Asia consists of so many diverse and different cultures. It was also understood that the term Asian is a sign that carries certain signifiers, as discussed by Alan

I find the word Asian quite broad to be completely honest I think it's a bit...I has connotations that I'm not completely comfortable with. I'd rather be called Vietnamese than Asian because I guess Asian, even in today's society isn't a good word... 
Being Asian in New Zealand also means finding commonality in experience with a myriad of ethnicities which fit under this category. ${ }^{31}$ Charles articulates this as a cultural experience which extends to ethnicities not traditionally understood as Asian.

... I really get angry when I hear or see examples of discrimination when European looking people who are foreigners don't get discriminated against because they look like the majority even though they speak with an accent or even off the street they don't get identified as a foreigner because they look white. But Asian people look different even if they've been three or four generations in New Zealand are targeted as outsiders. I could say the same about African people or Middle Eastern people, those other minorities that obviously look different from the majority tend to attract quite negative attention from people with racist agendas.

(Charles)

This demonstrates the problem with generalisations and how they encompass people who ambiguously align with the term. If we take Alan's idea that one cannot encompass all flavours of Asianness, then this poses a question for the nature of representation, especially in a museum context. How can we be inclusive without generalising? How do we respect individual experiences without diminishing a collective cultural experience? The participants found the idea of a prescribed identity contentious, however, they also felt a bond through shared experience, and although they had nothing in common with other Asian people were also drawn to them.

\section{Towards a commonplace}

These narratives cannot just be assumed as another part of the status quo of the national story. While focusing on their specificity there is also a need to recognise how these stories are part of a collective cultural experience of being Asian New Zealanders. The move away from emphasising the specialness and difference of Asian people in New Zealand is important. This needs to be achieved without disrespecting the unique experiences

31 Te Ara, the Encyclopedia of New Zealand categorises Asia as China, Japan, Korea, Laos, Thailand, Cambodia, Vietnam, Malaysia and Singaporeans, Indonesia, The Phillipines, India and Sri Lanka. I think this is partly because of the nationalities represented as part of New Zealand's population. 
Asian New Zealanders have faced because of the way we have been representationally and historically constructed.

Although the participants spoke about how they were somewhat outside of the term 'New Zealander', there was also a sense of simply being just another New Zealander. This is shown through the emphasis on characteristics they adopted that aligned with their ideas of being a New Zealander. They also felt separate from this term because of their experiences being represented or treated differently.

Charles thinks that status and sense of belonging could be helped by "normalising the multi-ethnic identity of who is a New Zealander." Also within Charles' suggestion of normalising multi-ethnicities he is aware of the need for an acceptance of Asian people within the national story, to be understood as New Zealanders rather than having their ethnicity ignored or not prominent. When asked how New Zealand could better accommodate Asian people in terms of representation he said,

It's not a zero sum game. Māori definitely have privileges that no other ethnic group can claim because they are the indigenous people, they are the first people here... Apart from looking at it from a numbers point of view, I don't think any particular ethnicity can claim there is some kind of pecking order. I mean all these minorities make up the New Zealand identity today.

(Charles)

Charles affirms Phillips' premise of New Zealand as a nation of immigrants (1996). However Charles' idea is a reaction to the model Te Papa has used in creating Passports where minorities are swallowed up as the other half of biculturalism. The problem with this is it is on par with the Pākehā experience which is very different culturally and experientially to Asian New Zealanders.

Cosmopolitanism advocates that human beings approach other human beings without the bias or prejudice of their signifiers and as "citizens of the world" (Kendall, Woodward \& Skirbis: 2009). Although this attitude is optimistic there are limitations. Firstly, in the world of representation, it is questionable whether it is possible for people to deny the loaded meaning 
of a signifier. We are culturally constructed to make signs and symbols matter partly via the museum; which is literally a storehouse of signifiers deemed significant. Also, from the interviews I have shown how meaning precedes and succeeds the encounter of the exhibition. Our experiences sit relative and relational to this encounter. The idea of cosmopolitanism discredits the fact that people's experiences are made up of the way they are represented and represent themselves. From the participants' stories it is also revealed that they do not necessarily have any desire to be citizens of the world but would rather be understood locally, here and now, as Asian New Zealanders in this time and place and have their experiences represented faithfully.

In terms of Alan describing his own affinity to other Asian people, he also stresses the lack of affinity with the signifier itself and a desire to communicate beyond an ethnicity which he feels ambiguously connected to.

To be completely honest, I do find myself shying away from Asian people... I'm not sure if that's like being scared of them or being ashamed of not knowing my culture too much or whether it's just how I grew up I don't know. I just don't find myself completely comfortable in that environment. I just find myself more comfortable in a European sort of situation as opposed to a Chinese one. (Alan)

The approach taken by Te Papa is nationalistic in the way it implies everyone fits under the category of 'New Zealander', however identity is never that simple to confine. Even hyphenating identities poses problems as it assumes identities are on equal par with each other.

It seems that if the question "where are you from?," is asked less, or if it were a ubiquitous question for all New Zealanders, not just non-Pākehā, then perhaps we have arrived at a commonplace idea of identity. It is about shifting this specificity and making the uniqueness of this experience universal.

You're the first generation of whatever or the second generation and I don't know if you'll ever be completely comfortable unless the whole society is multicultural and you feel your part of a huge 
heritage of mixes. But when you're a minority it's much more obvious you're not from here or you don't really connect.

(Bernice)

Connecting to identity is the key message in Bernice's story. Although we are ultimately left to decide for ourselves exactly who we are, it is about the idea of connecting which informs this perspective. Through the narratives being Asian or reacting to the idea of being Asian is an integral part of identity making.

It's really up to me so now when people ask me where I'm from. I say well my nationality is New Zealander, Kiwi but my ethnicity is Cambodian. So I won't say I'm from Cambodia because I'm not from Cambodia. I'm from New Zealand but my ethnicity, my background, who I am, is Cambodian cause that's always going to be a part of me. You know growing up for a long time... I didn't hate it but I found it really frustrating that I wasn't like everyone else and that I couldn't say I was completely Kiwi but now it's just something that I'm really proud of, and that only comes from being around a whole different range of people.

(Sarah)

The exposure of these identities - that they do not get swallowed up in the mainstream arena-is important. The uniqueness of voice, perspective, and experience is important to have at the forefront of understanding these identities. There also has to be respect that the process of identifying is not simple and that there are many negotiations involved in the process. For Sarah, she separates ethnicity and nationality and feels an affinity with both.

Something that was significant within the interviews was the idea of reflective identities and prospective identities. With reflective identities there is not only the idea of how one was, or how one reached their current state of identity but also the reaction of the self in relation to others and a perspective of themselves in terms of how they think they are understood. In terms of prospective identities-perhaps partly due to the age of the sample-there is also a forward, progressive look at identities that will ideally be arrived at and the course of action required to get there.

Bernice, Anna, and Charles discussed how it is important for them to understand where they came from in case it had to be passed on to later 
generations. Anna said "If I ever end up having kids then they kind of need to know where they come from."

For Charles who has a daughter, his connections and understanding of Asia are also part of the direction the world seems to be taking. When I asked him if it is important for him to maintain his heritage he replied

...I'm learning it [Mandarin]. You know but a lot of that is driven by the fact that China is going to be an important player in the future globally and I think it would be professionally advantageous to learn Mandarin. So I'm not making that decision to learn Mandarin simply because I feel it is fulfilling a missing part of my identity. I just think it's an incredibly useful thing to do. (Charles)

Perhaps it will be partly this political and economic direction which will help motivate cultural understandings of the position of Asian people in the world and the connection that is present locally. As political and reflective spaces, museums also have a part to play within this representation of Asian New Zealanders.

Bernice talked about an idealised feeling of belonging which was felt in regards to fitting in with other New Zealanders and in terms of her desire to feel connected to the Pacific. Her prospective identity is conscious of the changing nature of identity and she feels the need to leave New Zealand in order to find out who she is. Within this idea, she taps into the common New Zealand tradition of going on an overseas experience.

I would imagine with the generations passing it [culture] gets a little more diluted... I just kind of have a real need to leave the country to find out who I am. It's pretty much every New Zealander young or old do their $O E$ to find out what they're missing and I find that that's pretty much the same for me as well... My feelings about nationality, ethnicity that kind of stuff they will always change cause I can't rely on all the things I feel right now to be the same next year or next month or even tomorrow... (Bernice)

Perhaps this desire to leave is part of the understanding that distance-and the perspective that gives-allows greater clarification of how the self is understood and constructed. This also relates to Mitchell's argument where he describes the jaded feeling of seeing yourself and your culture 
represented because of the idea of the exhibition as a microcosm of the world (1998).

Both Charles and Anna want to go back to their respective countries of heritage and live there for some time.
I feel like I'm a New Zealander but then I watch Japanese movies, dramas and eat Japanese food and kind of feel like I want to go back there. One day I'd like to live there but then when I go there I just stand out. So I kind of can't call myself Japanese clearly but like I still have that sense of one day I wish I could go back to where my parents came from and spend a bit of time there.
I'd like to go back there [South East Asia] and live there at some point. I have a daughter who is quarter Chinese so it's part of her as well. I identify strongly with the stories of migrants, and they don't necessarily have to be ethnically the same as me but I can identify with their stories and can see many parallels between my family story and theirs.
(Charles)

Anna also commented on the prevalence of Asian culture saying that "plus a lot of people are into it as well now. It's becoming quite fashionable, the Asian thing." Awareness and the commonplace aspects of an Asian presence in New Zealand aid in helping people feel comfortable with that culture (Butcher, 2008). As seen in these two passages, identity making is something to look forward to and look back upon. Anna also discusses the vexed nature of identity and how practising culture and emotionally connecting to this do not necessarily intersect. From the interviews it is clear so far that there is no direct route toward arriving at identity and once arrived there is not straightforward way of identifying.

Alan is quite philosophical about his upbringing and how he saw himself being so assimilated into New Zealand culture that his Asian culture was, in a sense, left behind.

I'm guessing I'm on the side of the spectrum where I'm not too exposed to the Asian side of the culture which is kind of sad and I do regret it... If anything should happen to my parents I don't know anything ceremonial for them and think that would be quite disappointing. I think I would be quite disappointed in myself and I'm sure my parents wouldn't be so happy without me knowing about Buddhist funerals and 
things... And in terms of religion these things I should have picked up but I never did 'cause I was too busy being a Kiwi so I never did. Oh how dare I [laughs]. So that's how I grew up.

Time spent, too busy being a Kiwi, impeded on the connection to Asian customs and traditions that Alan would have learnt from his parents. There is a double bind between fitting in to the host culture and letting go of the systems and values of parental heritage.

When asked if he would ever 'go back to Vietnam?' Alan replied “my parents don't have any plans to go back and unless they go back I'm not going back." This idea of finding out 'who you are', or finding oneself, is talked about as a process still in the making. He talks about waiting for the right point to immerse himself into the culture. His idea of immersion is whole hearted and not merely attempting to simplify both cultures by combining the two.

For Anna her cultural view is accommodated by the idea that she creates her own culture,

I guess it is a mix of New Zealand and a little bit of Asian in a way. You can't take away what your parents brought you up on like the basic ideals. But there are some I like about the Asian culture and some things I don't like about the New Zealand culture and vice versa. I guess I just take the parts that I like and put them together.(Anna)

In this sense, identity and the creation of culture is about choice for her. It is reflective in the sense that she appropriates from her upbringing and surroundings.

\section{Summary}

The unifier of this group is experience that stems from being associated with that ethnicity but is also beyond the idea of ethnicity. Although identity is a contested and complex process all the participants were affirmative in who they were, who they are and who they will become. All the interviews ended on an optimistic note in relation to identity, and all confirmed themselves as New Zealanders. Just as research in the social 
sciences is a reflexive process (Sarantakos, 1998), so is the process of being and becoming.

I started this chapter with Anderson (1991) and Bourriaud (2009) showing how identity making and relating to each other is both intuitive and creative. The offshore identities of these participants never escape local idiosyncrasies. The journey of creating this identity is more important than the end point.

What became particularly compelling during the narratives were the tensions between connecting and disconnecting, between the intuition of feeling like a New Zealander and intellectually being constructed as a nonNew Zealander, and between being and belonging. Out of this tension emerges the communal experience which unified the participants and unifies Asian New Zealanders.

At the end of the narratives there was a great sentiment of optimism contrasting the critical lens in which they initially saw Passports and the somewhat difficult experiences they revealed about their sentiments of belonging in New Zealand. Mastering the survival tool of mobility and cultural adaptation, the Asian diaspora within New Zealand denies a nomadic state of mind, and is able to connect and relate to everyone, everywhere and everything. These later generations of Asian migrants are already in their place of birth and connection, with their offshore tug alluding to another type of prescribed identity, fabricated through a mediated New Zealand lens.

I guess at my age now, being 22, I feel like I fit in New Zealand more than I did when I was a teenager. Just now I realise that New Zealand is such a diverse place that even though my ancestors aren't Kiwi and I'm of Asian descent, that's like being brought up here. Apart from being Māori or Kiwi, I'm as Kiwi as anyone else here...I'm proud of it. I'm proud to go overseas and say I'm Kiwi and being able to say that I'm of Cambodian background but I'm fully Kiwi inside and out.

(Sarah) 


\section{Chapter 6: Conclusion}

If a man wishes to transform himself into a tree, he has to acclimatise himself to the speed of the tree's growth in its environmental conditions. Couldn't cultural differences be understood in this context? Another idea that I intended to consider in The Art of Transforming was the concept of identity. The changes which Asians have experienced during the past hundred years can be compared to the transformation of a human being into a tree. Our ways of living and conditions of living have been assimilated into those of industrialized Westerners whether voluntarily or not (Beom in Chong, 2010: 65).

The philosophy behind this dissertation is best described by Korean artist Kim Beom. The picture the museum has of a nation, of a community, does not necessarily match the group or person it corresponds to. They are going at different paces, both in attempts to match each other so that they are in a relevant direct conversation.

I began this dissertation by provocatively implying that museums were spaces of reaction and of danger. They are dangerous because they present a version of national identity which stands for and of the nation. Nowhere but Te Papa holds that same expectation or responsibility within New Zealand; to represent a collective whole and where to include and exclude are political acts.

This dissertation addressed two intersecting strands. Firstly, narrative interviews with Asian New Zealanders and how they create their identities in relation to representation. This was set within the context of the history of Asian people in New Zealand and how their representation has been contested. Secondly, this dissertation dealt with the changing nature of representation within the context of contemporary identity theory and the museum as a part of this circuit of representation. This was looked at in order to see what effects museum messages have beyond the museum's walls. The national museum is a space which deals with visual and material representation to convey knowledge about nationality, diversity and social inclusivity. At Te Papa this is done through the exhibition Passports. 
The initial aims of this research were to interrogate the idea of representing national identity as cohesive and to deconstruct Phillips' idea about New Zealand being a nation of immigrants (1996). I wanted to investigate what exactly the hybrid and cosmopolitan condition is through empirical testing to evaluate the efficacy of these and how they related to processes of representation both through the exhibition and the exhibited subject.

When I first embarked on this research I tried to examine contemporary identity theories to see whether or not new ideas and words were better suited to describe the position of Asian New Zealanders in this current moment. After I collected my material I realised that these categorisations were redundant to impose on the stories and thoughts of the participants. Being hybrid (Araeen, 2002; Bhabha, 1998; Meredith, 1998) or cosmopolitan (Kendall, Woodward \& Skirbis, 2009) may describe aspects of their lives but do not sum them up as a whole. These contemporary identity theories are also prescriptive contradicting my initial aim which was to show the evasion of categories because of these mismatched prescriptions. For example hybridity is premised on the idea of being exiled from both place of heritage and place of residence, however, the participants were confident in their sense of belonging to a place, and feeling like it's part of me as well, and an idealised sense of belonging.

After my analysis of Passports I feel that the museum is not a mirror but a manifesto, a place which reflects a societal aspiration rather than a reality. The focus Te Papa has used through Passports has attempted to celebrate the story of migration in New Zealand through focusing on the universal experience of hardship all migrants have experienced for both European and non European. Settlement is treated as something that has happened in the past and that we all have traceable histories. Passports supposes that we have adjusted to our current condition, affirmative in our sense of who we are. Through the narrative interviews I came to realize that the idea of migration has been abandoned but settling in this time and place is still an idea being dealt with. 
We have however, moved on to a new phase. Like the old prospectors of the early gold mining days, these new generations of Asian New Zealanders are also full of aspirations. Their point of difference however, is that whilst the old Chinese gold miners planned to strike it rich and return home, the new prospectors are already in their place of birth and feel at home. Their offshore tug is induced by a sense of displacement and alludes to another type of phantasm.

The specificity of experience for a communal social group, such as Asian New Zealanders, has been lost within this universality of New Zealand identity that Passports exhibits. Although Asian New Zealanders have also had a long history of settlement within this country, they are excluded from questions of national identity because they do not conventionally fit under the category of Pākehā. This is something considered as separate to the experiences of Asian New Zealanders as shown through the narrative interviews. As neither identifying as Māori nor Pākehā, the voice of Asian New Zealanders has gone astray within the bicultural discussion within Te Papa. Amending this would mean opening up the forum to include these voices as part of the Tangata Tiriti half of biculturalism, not just as another ethnic group but as a distinct cultural construct which has been created and influenced by being in New Zealand under these conditions. Te Papa's Level 4 exhibitions are divided from each other through ethnic and cultural categories, there is no distinct dialogue between the spaces. Mana Whenua stands separate from Passports, Tangata o le Moana and the Community Gallery. Perhaps there is opportunity within this, to somehow connect the narratives of these disparate exhibitions in order to create a more vigorous forum for debate.

Museums can aid in social inclusion and are spaces to have a connection and an experience. Within Te Papa's infrastructure they even have a team devoted to this called the "Experience Group" (Te Papa). ${ }^{32}$ What is lacking from Passports and what is emphasized within the narrative biographies

\footnotetext{
32 http://www.tepapa.govt.nz/AboutUs/pages/experiencegroup.aspx.
} 
was this feeling of experience. In Passports we are encouraged to encounter ourselves, to imagine we are aboard a ship, view objects that impose aura, read stories and facts that we can empathise with. It is all to create a sense of experience but the nature of history implies it is in the past, that where we are now is a different experience.

Passports aims towards inclusion by making visitors feel comfortable and familiar with the material on display, it is not necessarily unique objects we see but rather everyday, accessible items. Through the narrative interviews it became clear that the participants arrive at their identities through various epiphanies not only in thought but also through a physical experience.

I have alluded to the contested nature of trying to connect to material culture and instead of representing Asian New Zealander's through objects I propose an objectless exhibition where visitors are invited to experience what it is like to be an Asian New Zealander. From the stories I gathered, it is evident that the feeling of affinity, the feeling of dislocation, and the feeling of connecting is not one of representational signs or maps to finding out who you are but rather something embodied, visceral and intuitive. It goes beyond representation and is an experience of feeling rather than fact. The United States Holocaust Memorial Museum provides an example of how to treat the audience not as a visitor but as a participant in something complex, theatrical, and an experience which is not only intellectual but physical (Gurian, 2005).

Although the participants encountered a different experience of coming to terms with their multiple and sometimes conflicting identities, the feelings of being the same but different, of realising difference, of knowing something was not quite right, of feeling blurred, of feeling weirdly drawn to them, of not being able to describe who you are, of feeling like you're going against your culture, of concealing identity, of never questioning my identity, of having my identity questioned, of not knowing who to belong to, on being the 
transition phase, is indescribable as a visually articulated or intellectual experience.

The most recent Community Gallery exhibition, The mixing room, opened at Te Papa in April 2010 (Te Papa Concept Plans, 2009). ${ }^{33}$ This is Te Papa's first objectless community gallery exhibition, instead focusing on stories through films made with refugee background youth (ibid). This shows a direction away from ethnic categorisations. The people represented are not confined to being refugees but rather see this as a cultural state and situation (Te Papa Concept Plans, 2009). Perhaps this can reflect a wider shift in the understanding of identity as cultural situations which are in a state of flux rather than as ethnic, nationalist, homogenous, essentialist and unchanging.

The move towards an exhibition without objects also engenders a discussion on the role of national collections and how they can include and exclude through what is presented by the museum. I question whether objects are the best way to represent people as they have a reference pointing towards essentialist ideas. They are reminiscent of the dangerous process of representation layered with connotations and denotations of meaning (Lidchi, 1997).

This dissertation has only begun to look at the possibilities for an alternative communication of representation for the national museum. Because of the modest size of my research sample, and lack of room to go in depth to properly interrogate the theory, this dissertation aimed to contribute to a long and productive conversation investigating changing articulations of the nation, and our current condition of representing ethnicity in a country where this is increasingly significant due to a demographic change.

I use the term 'post ethnic' in the title of this dissertation. It is largely of my own creation. By post ethnic I mean an articulation of culture which is

33 When this research started the exhibition had not yet been opened. 
determined by ethnic categorization but not exhaustive of it. If Murphy's idea of identity is as a verb (2006), then perhaps culture is a practice. As Asian New Zealanders we inevitably have heritage tied to somewhere else whilst having roots here too, our history beyond ourselves determines who we are so prescriptively but we also have access to self-determination. We use strategic essentialism (Coombes 1998), identities to us are like layers and boxes that we pick and choose, playing the appropriate cards at the right time. What we bring to the encounter of the exhibition is not just a blank slate but everything we have come to know about our lives (Mason, 2005). We see, negotiate and interpret exhibitions and material culture relative to our own experiences, our vision is shaped by the position we stand within. Meaning emerges between how the museum interprets reality and our own comprehension of it.

In terms of implications for museum practice, perhaps the most appropriate way to approach the vexed nature of representation for Asian New Zealanders is through understanding the process of how they construct themselves. Begin by understanding that culture is a practice, something which is constantly evolving to be adaptable, translatable and respectful to both a local and global experience. The participants arrive at Asian forms not necessarily through an Asian vacuum but rather through a mediated, mobilised vision of what their position means.

There are no rules to the signs or things we should hold on to and the concepts we do appreciate such as an affinity with the people in our imagined community (Anderson, 1991) are too intricate and precious to be reduced to a single story or set of objects. Representation should focus on being complicated and not simple. If museums do not address this complexity they are at risk of being exclusive and irrelevant. It is just too dangerous. 


\section{Bibliography}

This bibliography is divided in the following sections:

A. Primary sources- archival material, electronic sources and Government publications.

B. Secondary sources- articles, books conference papers and theses.

\section{A. Primary sources:}

Asia: New Zealand Foundation, "Countries of Asia". Accessed 27 October 2010. http://www.asianz.org.nz/countries-asia.

Museum of New Zealand Te Papa Tongarewa, "About us: history." Accessed 27 October 2010.

http://www.tepapa.govt.nz/AboutUs/history/Pages/default.aspx\#1998.

Museum of New Zealand Te Papa Tongarewa, "Experience Group”. Accessed 27 October 2010.

http://www.tepapa.govt.nz/AboutUs/pages/experiencegroup.aspx

Museum of New Zealand Te Papa Tongarewa. (2009-12) "Statement of Intent 2009/10, 2010/11, 2011/12."

Museum of New Zealand Te Papa Tongarewa, "Passports." Accessed 27 October 2010.

http://www.tepapa.govt.nz/WhatsOn/exhibitions/Pages/Passports.aspx

Museum of New Zealand Te Papa Tongarewa Concept Plans. (1996)

"Passports 90\% Developed Design Part I Interpretation Objects."

Museum of New Zealand Te Papa Tongarewa Concept Plans. (2009) “The Mixing Room 90\% Developed Design."

Statistics New Zealand, “Glossary term: Asian peoples”. Accessed 27

October 2010.

http://www2.stats.govt.nz/domino/external/omni/omni.nsf/23f076d733 ded7e74c256570001d92b4/f327c02f3c289485cc25741a0005c53f?0penD ocument 


\section{B. Secondary sources:}

Anderson, B. (1991). Imagined Communities : reflections on the origin and spread of nationalism. London; New York, Verso.

Anderson, V. (2008). "The international education agenda: international and New Zealand Women students." Sites: a journal of social anthropology \& cultural studies 5(2): 57-80.

Anico, M. (2009). Representing identities at local municipal museums: Cultural forums or identity bunkers? Heritage and Identity. M. Anico and E. Peralta. Oxford, New York, Routledge: 63-75.

Araeen, R. (2002). A new beginning: beyond postcolonial cultural theory and identity politics. The Third Text Reader on Art, Culture and Theory. R. Araeen, S. Cubitt and Z. Sardar. London, New York, Continuum: 331-346.

Araeen, R. (2008). "A very special British issue? Modernity, Art History and the crisis of art today." Third Text 22(2): 125-144.

Ballard, C. (2005). The negotiation of narratives: A case study of the Indian community exhibition 'Aainaa: reflections through Indian Weddings' (September 2002-September 2004) at the Museum of New Zealand Te Papa Tongarewa. Museum \& Heritage Studies. Wellington, Victoria University of Wellington, New Zealand. Master in Museum \& Heritage Studies.

Bennett, A. (1999). "Subcultres or neo-tribes? Rethinking the relationship between youth, style and musical taste." Sociology 33(3): 599-617.

Bennett, T. (1998). Speaking to the eyes: museums, legibility and the social order. The politics of display: museums, science, culture. S. Macdonald. London, Routledge: 25-35.

Bourriaud, N. (2002). Relational aesthetics. Dijon, Les Presses du reel.

Bourriaud, N. (2009). Altermodern. Altermodern: Tate Triennial. N. Bourriaud. London, Tate Publishing: 11-25.

Butcher, A. (2008). "'Well, they're very good citizens': New Zealanders' Perceptions of Asians in New Zealand." Sites: A journal of Social Anthropology \& Cultural Studies 5(2): 5-30.

Chong, D. (2010). Kim Beom: a survey. Kim Beom_S. Kim. Seoul, SMUSO: Space for contemporay art: 14-115.

Coombes, A. E. (1998). Inventing the 'Postcolonial': Hybridity and Constituency in Contemporary Curating. The art of art history: a critical anthology. D. Preziosi. Oxford, Oxford University Press: 486-453. 
Cormack, D. M. (2007). Once an other always an other: contemporary discursive representations of the Asian Other in Aotearoa/New Zealand. East Asian Studies. Hamilton, University of Waikato. Doctor of Philosophy in East Asian Studies.

Demos, T. (2009). The ends of exile: towards a coming universality? Altermodern: Tate Triennial. N. Bourriaud. London, Tate Publishing: 72-84.

Denzin, N. K. (1989). Interpretive biography, qualitative research methods. California, SAGE.

Elliot, J. (2005). Using narrative in social research. London, Sage.

Fisher, J. (2008). Diaspora, trauma and the poetics of rembrance. Exiles, diasporas \& strangers. K. Mercer. London, MIT Press.

Fitzgerald, M. (2009). "Te Papa's Community Gallery: presenting migrant stories at 'our place'." New Zealand Journal of History 43(2): 198-206.

Fong, N. B. (1959). The Chinese in New Zealand. Hong Kong, Hong Kong University Press.

Foucault, M. (2004). Texts/Contexts: of other spaces. Grasping the world: The idea of the museum. D. Preziosi and C. Farrago. Aldershot, Ashgate: 371379.

Fujikane, C. (2008). Introduction. Asian settler colonialism : from local governance to the habits of everyday life in Hawai 'i. C. Fujikane and J. Y. Okamura. Honolulu, University of Hawai'i Press: 1-42.

Gibson, S. (2003). "Te Papa and New Zealand's Indian communities- a case study about exhibition development." Tuhinga 14: 61-75.

Grossberg, L. (1996). Identity and cultural studies: is that all there is? Questions of cultural identity. S. Hall and P. Du Gay. London, Sage: 87-107.

Gurian, E. H. (2005). A blurring of the boundaries. Heritage, museums and galleries: an introductory reader. G. Corsane. London and New York, Routledge: 71-77.

Hall, S. (1991). Old and new identities, old and new ethnicities. Culture, globalisation and the world-system. A. D. King. Basingstoke, Macmillan in association with Department of Art and Art History, State University of New York at Binghamton: 41-69.

Hall, S. (1991). The local and the global: globalization and ethnicity. Culture, Globalization and the World-System. A. D. King. Basingstoke, Macmillan in 
association with Department of Art and Art History, State University of New York at Binghamton: 19-40.

Hall, S. (1996). Introduction: who needs identity? Questions of cultural identity. S. Hall and P. Du Gay. London, Sage: 1-17.

Hall, S. (1997). The work of representation. Representation: cultural representations and signifying practices. S. Hall. London; Thousand Oaks, Calif., Sage in association with the Open University: 13- 74.

Hooper-Greenhill, E. (1996). Introduction. Cultural diversity: developing museum audiences in Britain. E. Hooper-Greenhill. New York, Leicester University Press.

Hooper-Greenhill, E. (2006). Studying visitors. A companion to museum studies. S. Macdonald. Oxford, Blackwell: 362-376

Ip, Manying, "Chinese" in Te Ara: Encyclopedia of New Zealand. Accessed 27 October 2010. http://www.teara.govt.nz/en/chinese/3.

Ip, M. and D. Pang (2005). New Zealand Chinese Identity: Sojourners, Model Minorities and Multiple Identities. New Zealand Identities: Departures and Destinations. J. H. Liu, T. McCreanor, T. McIntosh and T. Teaiwa. Wellington, Victoria University Press: 174-190.

Kendall, G., I. Woodward, et al. (2009). The sociology of cosmopolitanism. London, Palgrave Macmillan.

Lidchi, H. (1997). The politics and poetics of exhibiting other cultures. Representation: cultural representations and signifying practices. S. Hall. London; Thousand Oaks, Calif. , Sage in association with the Open University: 151- 222.

Liu, J. (2005). History and identity : a system of checks and balances for Aotearoa/New Zealand. New Zealand Identities: Departures and Destinations. J. Liu, T. McCreanor, T. McIntosh and T. Teaiwa. Wellington, VUP: 69-87.

Love, K. (2005). The experience of art as a living through of language. New responses to art and performance. G. Butt. Oxford, Basil Blackwell: 156-175.

Mason, R. (2005). Museums, galleries and hertiage: sites of meaningmaking and communication. Heritage, Museums and Galleries: an introductory reader. G. Corsane. New York, Routeledge: 200-214.

McCarthy, C. (2007). Exhibiting Maori: a history of colonial cultures of display. Wellington, Te Papa Press. 
McKinnon, M. (1996). Immigrants and citizens : New Zealanders and Asian immigration in historical context. Wellington, Institute of Policy Studies, Victoria University of Wellington.

Meredith, P. (1998). Hybridity in the third space: rethinking bi-cultural politics in Aotearoa/New Zealand. Te Oru Rangahau Maori Research and Development Conference. Massey University.

Mitchell, T. (1998). Orientalism and the exhibitionary order.The Art of Art History: A Critical Anthology. D. Preziosi. Oxford, Oxford University Press: 455-472.

Mok, T. M. (2004). "Race you there." Landfall 208: 18-26.

Murphy, N. (2006). "My New Zealand Identity." Aotearoa Ethnic Network Journal 1(2): 15-17.

Newman, A. (2005). 'Social exclusion zone' and 'the feelgood factor'. Heritage, Museums and Galleries: an introductory reader. G. Corsane. New York, Routledge: 325-332.

Newman, A. (2005). Understanding the social impact of museums, galleries and heritage through the concept of capital. Heritage, museums and galleries: an introductory reader. G. Corsane. London and New York, Routledge: 228-237.

Pamphilon, B. (1999). "The zoom model: a dynamic framework for the analysis of life histories." Qualitative Inquiry 5(3): 393-410.

Papastergiadis, N. (1998). Dialogues in the diasporas: essays and conversations on cultural identity. London ; New York : Rivers Oram Press ; New York, New York University Press.

Pearce, S. (1996). Making other people. Cultural diversity: developing museum audiences in Britain. E. Hooper-Greenhill. New York, Leicester University Press.

Phillips, J. (1996). "Our history, our selves. The historian and national identity. ." The New Zealand Journal of History October 30(2): 107-112.

Phillips, Jock, "The New Zealanders" in Te Ara: Encyclopedia of New Zealand. Accessed 27 October 2010. http://www.teara.govt.nz/en/thenew-zealanders.

Pieterse, J. N. (2005). Multiculturalism and museums: discourse about others in the age of globalization. Heritage, Museums and Galleries: an Introductory Reader. G. Corsane. London and New York, Routledge: 163183. 
Preziosi, D. (2009). "Enchanted Credulities: Art, Religion and Amnesia ." Xtra 11(1).

Rouse, J. (2007). Lisa Reihana: beyond the ethnic imaginary School of Art History, Classics and Religious Studies. Wellington, Victoria University of Wellington. Master of Arts in Art History.

Sandell, J. D. a. R. (2001). Including museums: perspectives on museums, galleries and social inclusion. Leicester, Research centre for museums and galleries.

Sandell, R. (2002). Museums and the combating of social inequality: roles, responsibilities, resistance. Museums, society, inequality. R. Sandell. London, Routledge: 2-23.

Sandell, R. (2007). Museums, prejudice and the reframing of difference. Oxon, Routeledge.

Sarantakos, S. (1998). Social research. Basingstoke, Hampshire, Macmillan.

Saukko, P. (2005). Methodologies for cultural studies: an integrative approach. The SAGE handbook of qualitative research. N. K. Denzin and Y. S. Lincoln. Thousand Oaks, Sage Publishing: 343-356.

Scott, C. (2002). Measuring social value. Museums, society, inequality. R. Sandell. New York, Routledge: 41-55.

Shayne Walker, A. E. A. G. (2006). "An exploration of kaupapa Maori research, its priniciples, processes and applications." International Journal Social Research Methodology 9(4): 331-334.

Silverman, L. H. (2002). The therapeutic potential of museums as pathways to inclusion. Museums, society, inequality. R. Sandell. London, Routledge: 6983.

Stam, D. C. (2005). The informed muse: the implications of 'The New Museology' for museum practice. Heritage, Museums and Galleries: an introductory reader. G. Corsane. Oxford, New York, Routledge: 54-71.

Stivers, C. (2009). Reflections on the biographical turn in social science. Life story research. B. Harrison. London, SAGE: 179-190.

Waite, J. (2009). Under construction : national identity and the display of colonial history at the National Museum of Singapore and the Museum of New Zealand Te Papa Tongarewa. Museum \& Heritage Studies. Wellington, Victoria University of Wellington. Masters in Museum \& Heritage Studies.

Ward, C. and E.-Y. Lin (2005). Immigration, Acculturation and National Identity in New Zealand. New Zealand Identities: Departures and 
Destinations. J. H. Liu, T. McCreanor, T. McIntosh and T. Teaiwa. Wellington, Victoria University Press.

Wengraf, T. (2001). Qualitative research interviewing. London, SAGE.

Wood, P. (2005). "Community consultation: Te Papa and New Zealand Indian communities- the other side of the coin." Tuhingha 16: 127-135. 


\section{Appendix 1}

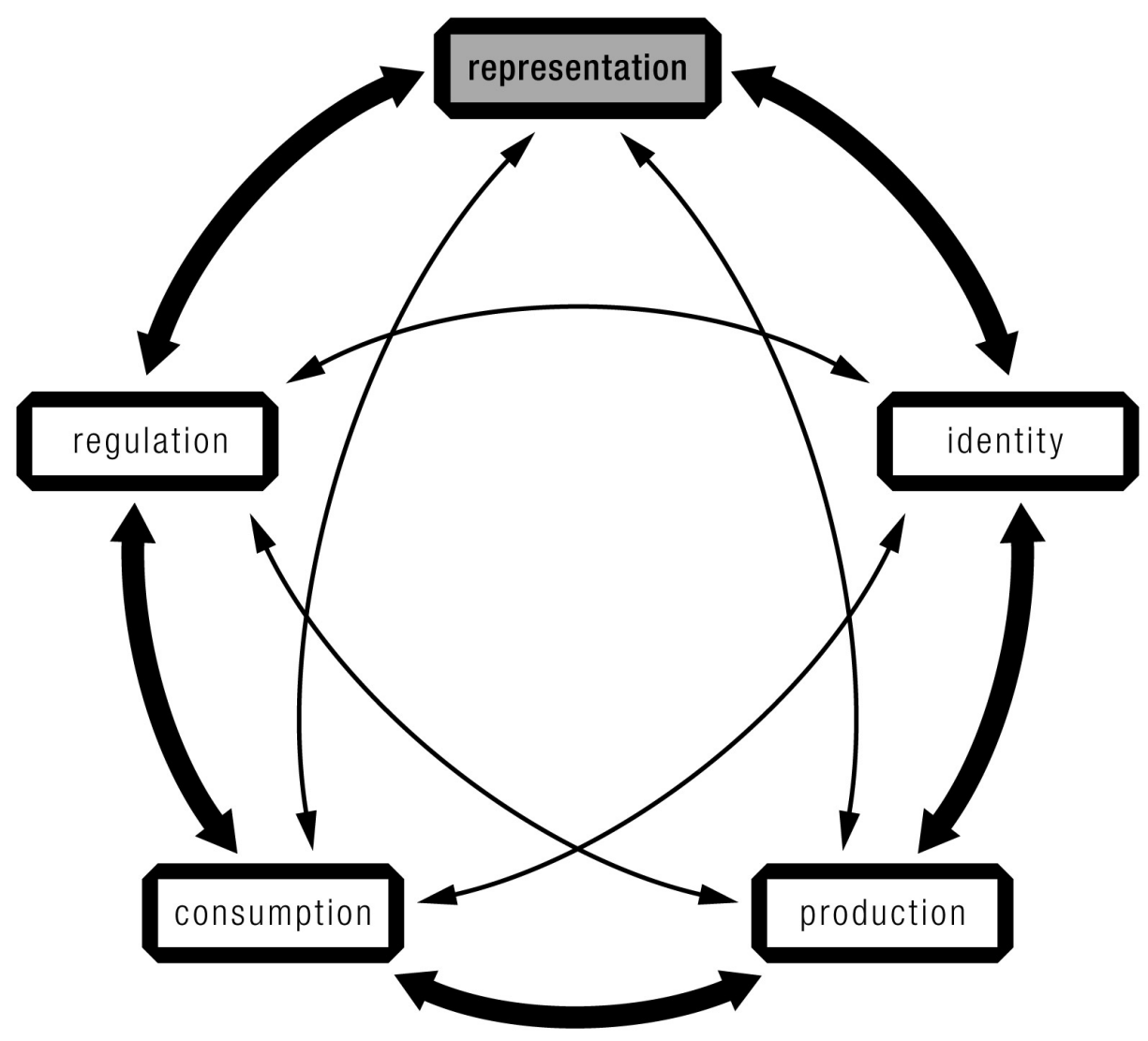

“Circuit of culture," (Hall, 1997: 1). 


\section{Appendix 2}

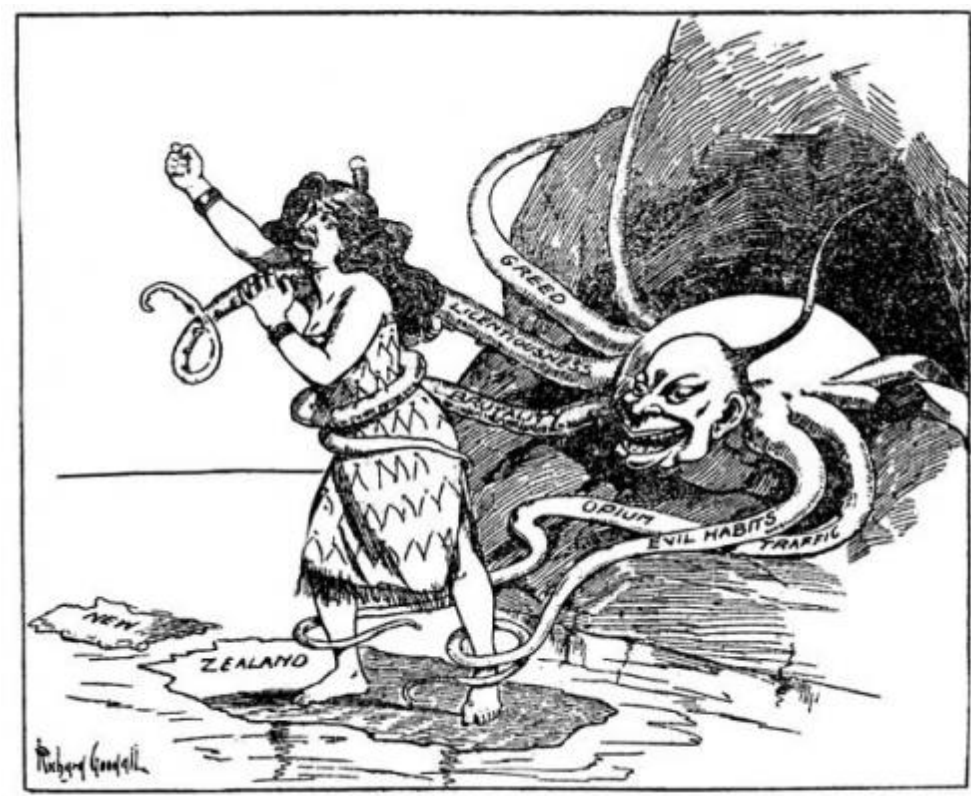

THE YELLOW PERIL.

Richard Goodall, New Zealand Truth, 16 February 1907

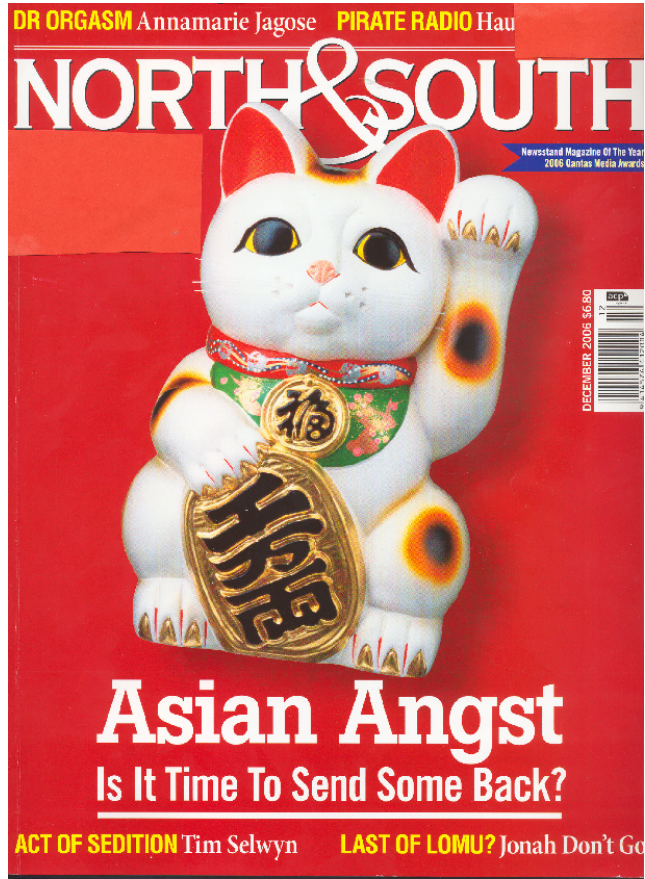

North \& South, December 2006 


\section{Appendix 3}

\section{Sarah's Transcript}

\section{Interview part 1}

Vera: I would like you to please tell me about your feelings of belonging in New Zealand. Perhaps we can start with the exhibition, is there any material you connected with? I will not interrupt and will be taking notes. Please talk for as long you like.

Sarah: When we were there I saw the goldmine part and not just because the photo was of people of Asian descent, but also I just kind of thought that the people that come here are the people that really work and really work hard to make a living for themselves, and just to provide for their children and have a better life than they would where we're from, Cambodia. So I guess that's how it related to me the most in the exhibition and I guess that's how we kind of had a sense of belonging in New Zealand, being a part of New Zealand was by working hard, its just always been a part of our lives cause we didn't come here out of choice really. It's because we had to, well not me but my parents yeah to have a better life to get away from the war and things like that. The only way that they could really belong was to work.

Vera: Do you want to expand more on that, on your background?

S: So we're from Cambodia. My parents are from Cambodia. I think maybe my great, great grandfather was maybe Chinese so we have Chinese blood in us but I consider myself probably full Cambodian. And the reason why we are in New Zealand is because of the war in Cambodia and the Khmer Rouge and Pol Pot so in Cambodia my parents weren't poor, they were well off, their parents had a business and they did very well. And it was when they were put in a labour camp for four years and my two uncles, one was already in New Zealand one was in America the one that was in New Zealand sponsored my parents to come to New Zealand so they came here about thirty years ago with no money and pretty much nothing and didn't know any English. And I was born 1987 my brother before that and another younger brother and younger sister after that can't remember the years sorry. Do you want me to keep going? So when my parents first came to New Zealand my parents worked in various factories basically doing labour work so now I'm trying to think back to my research for my project. He worked in a cardboard making factory so he made cardboard boxes and then from there on he moved on to other places making wire and stuff like that. The only reason why he moved on is because he was made redundant but every time he went to find a job it would literally be walking down industrial districts and it would be walking and asking "can I have a job?" He barely knew any English he would just be like "can I have a job, I'll work I'll come in on this day," sort of thing. And... that's how he first started working in New Zealand. And my mum didn't work. She raised my brother 
and stayed at home with my two uncles and my sister cause my grandparents passed away during the war, so my mum and dad raised my uncles and my aunty as their own children, so my mum was a lot younger than me probably eighteen or nineteen carrying my brother, pregnant and so she grew up really, really quickly with no parents. And I think that's what shaped me a lot as well like even though I didn't go through their hardship, it's something I'll always go through in the back of my mind or just always something in the back of my mind is something to... Just morals to live by if there's any hardship I go through or feeling really down or if something's not going well for me then I'll just be like okay well, you know, at least I didn't have to go through a war in Cambodia and escape from Cambodia to another country where I didn't know the language. I'm quite privileged compared to what my parents went through and that's something I've always lived by. And something they've always told me when I was young, was just how lucky I am that you were born in New Zealand so, "you were born in New Zealand and you are very lucky and we never." And my mum would always say I've always wanted to go to school and so you should always try hard in school cause if I could go I definitely would sort of thing. So it's not like they were forcing me to live a life that they couldn't have but it was just something that I was always thinking about all the time and I always keep that in my head. It's made me want to do well in my life in New Zealand.

Vera: Perhaps tell me more about life in New Zealand?

Sarah: So...I was born in Wellington in Strathmore and when I was young we moved to Winstone Place in Johnsonville and my first language was actually Cambodian. I didn't speak English to start off with because before I got to school apart from television, I wasn't around any English cause my parents still spoke Cambodian to me. So I didn't know any different. I was pure Khmer growing up. It wasn't till I started going to school that I realised that you know we are a little bit different. You don't really notice it when your younger but growing up when people or children are at an age who can judge you and your around say, your best friend who is Kiwi with blonde hair and then you notice okay, I'm different, and then you go over to their house and go over to play and that's when I started to notice things were quite different. So I grew up in Winstone Place and pretty much maybe after a few years in primary school, late primary school, just about to enter intermediate I forgot all my Cambodian just because I barely spoke it. I think at home I still speak a bit of it, just because my parents still speak it to me cause I understand it fluently, but its not until I start to speak it it's when I realise oh, I'm not making any sense, I have a really bad Cambodian Kiwi accent. What else.... [long pause]... It bothered me a bit that I was different when I was younger. Around intermediate when I was about 10 or 11 when I used to get picked on. I don't know why I was bullied but I was singled out by a group of girls and I'm not quite sure why. I think it's just that age when people do just single out other boys or girls and just bully them but I was picked on quite a bit at intermediate and it bothered me because I knew I was slightly different. Things like going to the mall after school, cause I went to Raroa and after school everyone would go to 
Johnsonville Mall just to hang out there and I would have to go straight home because my mum would just wonder what is the point of going to the mall and hanging out? "You shouldn't do that because we don't do that. You come home straight after school." I mean, I wanted to hang out with them cause I wanted to fit in but then.... You know, it was we just have to come home and study that was about it. It wasn't until form two that I asked to get put in a class different to those girls, and that's when I met Ida and she is a friend that I met when I was eleven and she is still one of my closest friends now because she was one of the people that I felt really, really close to, because she's Malaysian and her parents have brought her up almost exactly the same as my parents. You know it's not about going to school and then afterwards going to the mall. It's about spending time with your family and brothers and sisters and just I'm not trying to be racist or anything, but you kind of automatically are attracted to people who look like you and you feel more comfortable and are able to express yourself, kind of thing. So me and Ida stuck together quite a lot a bit and she went to Wellington Girls the same year as me and she left about fourth form but every time she's gone away for a few years and then we've met up its just like she's never left. It's just someone, she's just someone that I really relate to and I'm really comfortable being around.... In college... I wasn't bullied in college but I started to feel in college is when I started to feel like what's the word... That's when I started to feel like I was against my mum. I just felt like, not against her, but I started to realise how strict she was and how strict how she brought me up and really compared how she raised me and the way that Kiwis are raised. How she emphasised a lot about study she didn't want me to work at all growing up. You know like I always saw that Kiwi kids when they reach teenage years thirteen, fourteen, their parents wanted them to go and find a job and earn money for themselves and have their own pocket money. Whereas in our family my mum would never ever encourage me to work. I got my first job when I was fifteen but that was against mum and dads wishes. Oh dad probably wouldn't have minded but mum was always about study, "you don't need to work because me growing up me- your dad and I are the hard workers we're the ones that are providing for you, and you're the one that needs to go study and you don't need to have such a hard life like we did," sort of thing and I guess... At first I didn't see the point of it. I thought it was stupid I can do this all myself, I'm growing up I know... I know I can handle studying and having my first part time job or whatever. All I want to is get a job at Macdonald's or Woolworths or something just so I can have some pocket money just so I wouldn't have to ask her for twenty bucks every week, so I have my own sort of freedom, so I can go and spend money whenever I want but... No, my parents didn't allow it just because they wanted me to focus on studying. Also on top of that it was the issues of making friends with the right people and boys. Growing up I was never ever encouraged to talk to boys. Mum and dad treated my brothers a bit differently because they're guys and yeah she'll sort of tell them the same thing, but say if my brother went and did something, she'd just let him of the hook quite easily whereas she'd just focus more on me because I'm female, I'm a girl. I always tried to tell my mum you know, in this country they treat female and male equally 
and I went through a feminist phase in college and high school where we learned about feminism in history and suffragettes and stuff. So I got into feminism quite a bit and I always told my mum you should really treat me the same as Bunna and Michael because in this country everyone is treated the same blah blah blah, and them my mum would always tell me, "it doesn't matter because you're not Kiwi your Cambodian sort of thing. That's how we raise you your living in New Zealand but your raised as a Cambodian." Yeah, growing up as a teenager a lot of the time I just thought it was really silly and I always considered myself Kiwi because I was raised here and I was raised around Kiwi people all my peers. So yeah boys were never encouraged to talk to even having them as friends or acquaintances was pretty much frowned upon. You know if they called on the phone just a friend my mum would be nagging, "who was it, why you talking to them blah blah blah." Like it wasn't acceptable for me to just talk to boys. It bothered me a lot because in Kiwi culture it's fine, you have a guy friend and it's fine. In Cambodian culture it's not, you talk to guy it's like, are you going out with him? Do you like him? That bothered me heaps because you can't avoid it growing up as a teenager and your pressured by your peers a lot of the time to, not directly, but, just when girls of my age were seeing guys and dating and stuff you feel really, really left out the fact that their parents are fine with it and that, you know, when your definitely not allowed to have a boy call. It just bothered me a lot and that's when I realised that my upbringing is so strict and my parents are so protective and I had even had some of my friends say "your mum is so protective she never lets you go anywhere." After school I was always going home whereas because we went to Wellington Girls' it's in town, after school you want to go to town and hang out. Just like intermediate you don't go to the mall after school you have to go home and study. It wasn't until Uni, first year Uni that I started to really... not rebel, I think I got out of my rebellious phase in high school, sorry this is reverting back again. I think because I was brought up in such a protective sort of environment I felt the need to really, really fit in. The way I rebelled was to do things behind my parents back because I really, really do respect my parents and I love them so much I would never do anything to hurt them directly so anything I did I knew they wouldn't approve of I did behind their back. For example boyfriends growing up and going up late at night. I would say I'm staying at someone's house at a friend's house I would never do anything directly and would just walk out the door and do it under their noses and not in front of their face cause that would really hurt them. And I would never ever directly hurt my parents just because I respect everything they've ever done for me. I'm getting emotional [laughs].

Vera: Are you alright?

Sarah: I'm just thinking, I'm thinking back to like when I was a little shit. I can't believe I did that stuff.

Vera: It's okay, do you want to stop or... 
Sarah: No, no it's fine. I'm just trying to make it make sense... Yeah so, when I was young growing up I was always told stories, my mum would always put me to be and she'd tuck me in and just tell me stories about the war and how hard it has been to come to New Zealand and to raise me in New Zealand and have kids in New Zealand and just basically just come to a completely different country without any English and without any possessions really. Because she did it so often. It's just always been with me. I was young, say ten years old she'd tucking me in and telling me stories about how she'd be walking through the jungle with my dad with her brothers and sisters and seeing dead bodies hanging through trees and stuff. It's probably not something you should tell a ten year old but she used to tell me every single night and I'd listen. When I was younger I used to just listen but when I got a bit older in my teenage years when my mum would tell me those stories I'd start to get really, really emotional cause that's when I started to realise how hard it was because you know when you're so young you don't realise how lucky you are. It's not until you grow up its when you realise. I think that's why I never have tried to directly hurt my parents by disobeying them in any way. As much as I wanted to fit in with my peers I would never do anything to disobey them. But I did anyway I did rebel a bit. I wagged school and I made friends with the wrong people. The thing is, I made friends with the wrong people but I knew I made friends with the wrong people. Like I knew I wouldn't be friends with these people forever. Just people that if they weren't that smart that didn't focus on their studies and people that were a bad influence. I made friends with those people because they made me feel like I fit in. I just felt like hanging out with them. I don't know. Like everyone else. First year Uni I grew out of that cause I turned eighteen so getting alcohol and things like that weren't illegal cause I could just go out and buy it myself. It wasn't naughty I had kind of grown out of all that going out late at night and all that stuff. So first year Uni I focused a lot on studies more and trying really, really hard at school cause I wanted to get into second year. This was at design school and also in my first year I made friends with tonnes of International students, those Thai girls. I didn't straight away. Straight away I didn't really get along with them they just kind of hung out by themselves and I was like "oh my god so many Asians in that corner." I didn't really talk to them that much it wasn't until I had my birthday that year that I decided to invite pretty much the entire first year studio. I gave them my invitation and I decided to be really friendly to them and they decided to come and then from there we just became really good friends. Later on they revealed to me that they thought I was an absolute bitch they didn't even like me. Their first impression, they didn't like me, they just thought I was stuck up and apparently my demeanour... I'd come across as really grumpy and stuff like that which is fine but I think its because they know, you can just tell that we're different. Like we're both from South East Asia or whatever but because they're International students they just, I think you can just tell, maybe just by body language, who you hang out with, what you wear and things like that so to them I was really, really Kiwi. But we look the same you know? Hanging out with them we became really close and because I went to Thailand in the summer time I got to hang out with them in 
Thailand and for some reason I felt really close to them. Like I belonged with them as well. Like I felt like I fit in really well with them even though they weren't Kiwi but at the same time I feel like I fit in with my Kiwi peers as well. I started to feel really just grateful that I had a different upbringing to them. Because I do get along with people, like I never really... What's the word? I wasn't exclusive to an exclusive group of people and that became really apparent in $7^{\text {th }}$ form you know where you have the cliquey sort of groups. Like you have the nerdy girls and the popular girls who think they're hot shit cause they all have boyfriends and they're all pretty and stuff and the sporty girls. I remember in $7^{\text {th }}$ form I hung out in the art rooms every single day but if I went to the common room I could pop round to every group and talk to at least one person in each group. Like I was friends with everyone or not exactly friends with everyone, but I got along with everyone. So in Uni I became grateful for that that. I was able to get along with a whole range of people and... What was I going to say... In first year Uni like I hung out with a lot of the Asian crowd, both International students and Kiwi Asians. That was the first time I had so many Asian friends... Like I don't know how they came along. Do you remember in first year how I hung out with only Asian people for ages? That probably went into second year as well. I just remember John and Chang and all the people that used to hang out with Alex we were all Asians but Kiwi Asians as well which is really cool. I'm just trying to think where I was going with this. So that was first year Uni and second year Uni so I was about nineteen/twenty after second year I moved to Massey. After I moved to Massey I kind of lost contact with my International student friends cause they kind of all stayed at Vic. I started to make new friends at Massey. I didn't make that many closer friends, my closest friends that I stuck with were a couple girls or a few girls from high school and that was about it. That's also when I started working in hospitality in Uni and I started making friends with people who didn't study. They all just worked in hospitality and they all just were a huge range of people. They were younger than me and they were older than me and some were Kiwi and some weren't. These people I would, I think that these people are really unique because you need to have a certain personality to work in that industry...Yeah a personality that you can get along with other people and I worked in that industry for quite a while. I am working in that industry for quite a long time and I started to make lifelong friends that I didn't meet through school and I didn't meet through Uni and I started to kind of appreciate my background and uniqueness and how...being I don't know...I guess I felt like I really got along with those people in hospo because I grew up with such a different background and I tried so hard to fit in for such a long time that starting to work in hospo, I just realised that there are just so many different people out there and it just really depends, it doesn't really matter where you came from or where you were brought up it just depends how you carry yourself really... Yeah also cause everyone came from such a different background and cause I look Asian people always asked where are you? People are always curious and I hadn't been asked that so many times before working in hospo. And I started to think, how do I even explain where I'm from cause a lot of the time people ask me and all I say is New 
Zealand cause I was born here but then I do look different from other people. So I think how am I supposed to explain this, where I'm from, so I decided that there isn't any proper way to explain where I'm from. It's really up to me so now when people ask me where I'm from I say well I'm from, you know, my nationality is New Zealander/Kiwi but my ethnicity is Cambodian. So I won't say I'm from Cambodia because I'm not from Cambodia I'm from New Zealand but my ethnicity, my background, who I am is Cambodian cause that's always going to be a part of me. You know growing up for a long time... I didn't hate it but I found it really frustrating that I wasn't like everyone else and that I couldn't say I was completely Kiwi but now its just something that I'm really proud of and that only comes from being around a whole different range of people.

Oh! Another thing, when I was younger in primary school there was one thing that always bothered me was when teachers would ask you, say it was history or social studies, and they would say "go home and ask your parents about this, this TV show they probably watched it when they were younger." I could never go home and ask my mum oh my social studies told me to ask you about a TV show in the 80s that everyone watched like what was that character from that show I could never go home and ask that because they didn't grow up here. It's just something that's always, always bothered me when I was younger. Just little things like that bothered me in a negative way but now I look back at it and you know I'm just I don't mind it at all. It's something that makes me different from everyone else. I think there was a whole bunch of other stuff I wanted to say but its just gone. I can't think of anything else.

[Pause]

I guess at my age now, being 22, I feel like I fit in like a New Zealander more than I did when I was a teenager. Just now I realise that New Zealand is such a diverse place that even though my ancestors aren't Kiwi and I'm of Asian decent that's like being brought up here. Apart from being Maori or Kiwi, I'm as Kiwi as anyone else here. Which is really cool. Like I'm proud of it. I'm proud to go overseas and say I'm Kiwi and being able to say that I'm on Cambodian background but I'm fully Kiwi inside and out.

\section{Interview part 2}

Vera: I'm just going to ask you some questions in response to the wonderful story you gave me last week. You talked about how you have Chinese heritage from your parents. Do you have much of a connection to that?

Sarah: I don't consider myself Chinese, a lot of people mistake me for... You know when people try and figure out where I'm from they might say Ni hau and think I'm Chinese but then I'll be like...I don't get offended, I get offended in the sense that people think all Asians are Chinese but I don't get offended that people think I'm Chinese. It's just like, sometimes if its done in quite a provoking manner I will get quite insulted by it, just because it's just ignorance. I don't feel a close connection... I guess the connection we do have are sort of like beliefs and things like Chinese horoscopes and 
beliefs like Chinese culture you know in a fish tank every Chinese restaurant has a fish tank and the black fish is the one that absorbs all the evil in the fishtank and stuff that's why we have so many black fish and things like that which we still do which I relate to but in terms of Chinese heritage and things like that not really. I just know we have Chinese blood, like I say I'm full Cambodian.

Vera: So what to you is being Asian?

Sarah: Being Asian... What to me is being Asian... I guess I think it's a lot to do with the way I was brought up and parents yeah I think that's what. What's the question? What to me is being Asian? I think to me it's the just way I was brought up, yeah I think it is my parents, I look Asian but at the same time you know I think the most Asian thing about me was the way I was brought up. We were brought up so differently that's how I differentiate myself from a Non-Asian person. Apart from my parents.

Vera: What to you is being a New Zealander?

Sarah: Being a New Zealander is, I guess growing up in New Zealand away, outside of my household. I guess being at home is being Asian and being outside of home is being Kiwi. It's like being out in the environment. You're being brought up around other New Zealanders.

Vera: Is that hard to be both?

Sarah: Yeah...Oh it's not now. I've just only starting coming to peace with it recently that I've just become, figured out who I am and figured out what I want to do and my goals and things but before yeah it was hard. I think I accepted it a lot easier than my siblings. Oh maybe Michael not so much Michael's alright with it, but my older brother and my younger sister they're struggling with it quite a bit and I can tell but I do think that being brought up this way is probably a route to a lot of issues I've had before but it was difficult but now I'm at peace with it and I'm proud of it and I'm happy with it. I don't regret it at all.

Vera: What do you mean by fitting in? What to you is fitting in?

Sarah: ...Basically just not being seen as someone who was brought up differently. Just being able to do whatever I want without someone having to...I guess that's just sounding like a rebellious teenager but more like being able to do what the other people could do around me as well but having my parents accept and support that because they never really did. Those sorts of things like concealing it and concealing being Kiwi from them was because I thought they would get hurt by it oh you know "you're Cambodian you don't do the same things as those people." Whereas at the same time as being what my parents wanted me to be. Yeah it was quite conflicting.

Vera: You talked about how at university you became friends with lots of Asian people. Did you have anything in common with them? What made you connect to them? 
Sarah: I don't know...I don't think I had much in common with them because I think if they weren't Asian I wouldn't have been friends with them. I know that's quite weird to say but I was just weirdly drawn to them. I don't know if it's because they look like me but at the same time I know that their upbringing would be similar to me. We never talked about it. "Oh you were brought up like this." Kind of thing. Even though, I think their morals and stuff they were brought up the same but at the same time different because they were International students because pretty much their parents are loaded and pay for everything. So, it's different in that sense but I think just the whole Kiwi, Pākeha Kiwi thinking and Asian thinking its just slightly differently. I think subconsciously you just get drawn to it. But yeah I think that's all we had in common with each other. I think if they weren't Asian...half of the time some of them weren't even my type you know just hung out with them anyway. We were all drawn to this crowd. But it was fun, yeah.

Vera: So growing up did you feel peer pressure to just be Kiwi?

Sarah: Not, no... I wasn't purposely peer pressured but I think I felt pressure from myself to fit in with them. But they didn't deliberately pressure me just things like parties and I don't know what else just those sorts of things that are just so growing up Kiwi teenage culture its just so normal. To me it's just like such a struggle to be able to do those things.

Vera: So that leads me to my next questions which you've kind of covered but were there specific things that made you feel like you were going against your culture? Or activities, ways of being...

Sarah: That stuff it's not going against, it's so normal to Kiwi culture like I think Kiwi parents accept it cause that's just what they do. Whereas our parents are just like "that just never happens" "No you don't do that" "Just because you're living here doesn't mean you can do it, cause your Cambodian." Kind of thing. Whereas we were always encouraged to study, study, study, study, all the time, and our free time was home time like hanging out at home. Like hanging out at home and doing nothing is normal.

Vera: How do you think your parents' story and how their culture has shaped you?

Sarah: It makes me really sort of appreciative of what I've got and it makes me strive to reach my goal just because I, you know, I got the whole clichéd story of "your so lucky that you were born here and we didn't get that chance," and yeah that's a cliché which I hardly ever thought about until now. It does hit a cord with me sometimes where I feel quite really blessed, like when good things happen I feel really, really blessed and just because my parents never had the opportunity so when something good does happen it's really exciting for me, because I feel like they're going to be so proud of me. What affects me really affects them as well. 
Vera: And do you think your culture and your world view that you've created for yourself, how do you think that's different from your parents?

Sarah: Yeah it's really different. Where I think I've gotten the best of two worlds. Whereas yeah they live here but they've always held on to what they are and while living in another environment, whereas I live in another environment but I embrace both, sort of both things/cultures around me.

Vera: And you know last time you talked about how little cultural references bothered you, how would you like that to change? In what way?

Sarah: I don't know, you mean like what would have made the situation better?

Vera: I guess so, yeah.

S: I guess if people just didn't assume. I think it would...you know my view of a New Zealander and a Kiwi is like, like I think I said last time, I am the ultimate Kiwi like you can't get anymore Kiwi than me even though my parents and their background are from somewhere else so I guess...It's like now like maybe back in the day when I was really little, sort of stereotypical Kiwi kid was you know like Pākehā like grew up in Masterton or something like that, went down to the dairy and shops and stuff. I think it's changed dramatically and if people just didn't assume. I think its not a big deal its not like its offends me or anything but there is a dramatic change now.

Vera: How do you see that change happen? How do you see the position of Asian people in New Zealand now?

Sarah: What do you mean?

Vera: I guess in the public...like what do you see at the position of Asian people in New Zealand?

Sarah: I think there's a few different ways. I see people coming to New Zealand or coming to New Zealand for a purpose like say International students or coming to work and things. Or I see Asian people that grew up here and become Kiwis. But at the same time the people that are International students and came here grew up somewhere else and came here when they were 15 for example Nguyen. I think its changing the fact that she can call herself Kiwi now, like she would call New Zealand home you know. Even though Vietnam is her home and she loves it so much but I think now those sorts of people would be comfortable to call New Zealand home as well and would be comfortable to be accepted. Whereas before not so much accepted, like they were a lot more alienated or we were a lot more alienated.

Vera: How would like to be represented in the museum?

Sarah: In a museum...I think as just Kiwi born Asians I guess, New Zealand born Asians. I guess that's giving it a title though. I guess sort of 
represented as the group that got the best of both worlds almost. Like the sort of transition phase.

Vera: And so do you see yourself as similar or different to Asians in New Zealand who were born here. For example the friends that you had at university?

Sarah: I don't know. I think half and half, it's really hard to gauge that cause I think it just depends on the other person's background as well. Yeah just depends because those Uni friends I think I felt a lot different to them whereas with someone like Nguyen just because she's close to me, but someone like Nguyen I find myself very close and very similar to her but at the same time there are so many different things. I don't know, it's really hard to gauge. I think half and half like I wouldn't say that I'm very far removed from them because I'm not and I also wouldn't say that they're the same as me because they're not either. 